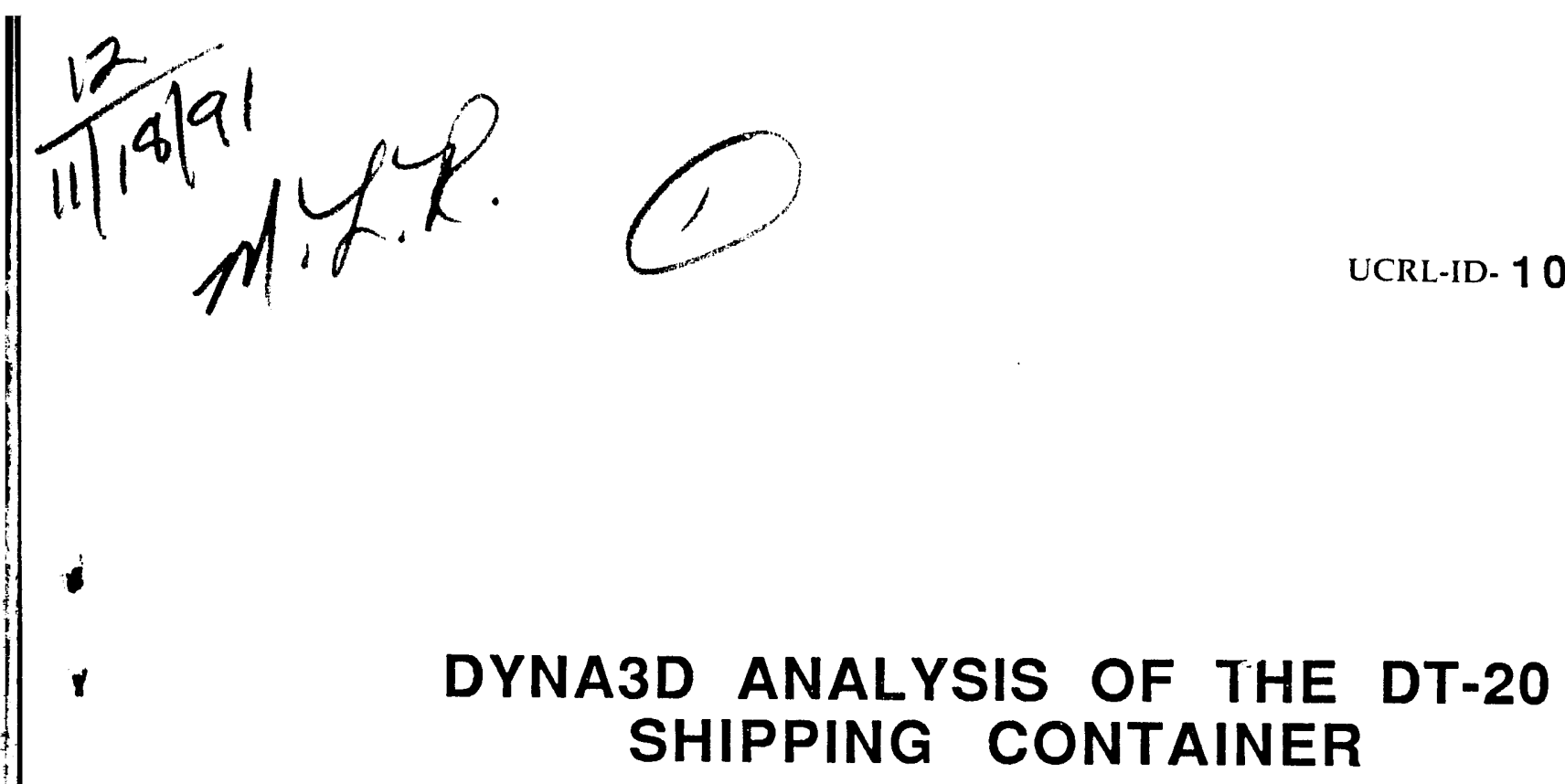

\author{
R. W. Logan \\ S. C. Lovejoy
}

August 22, 1991

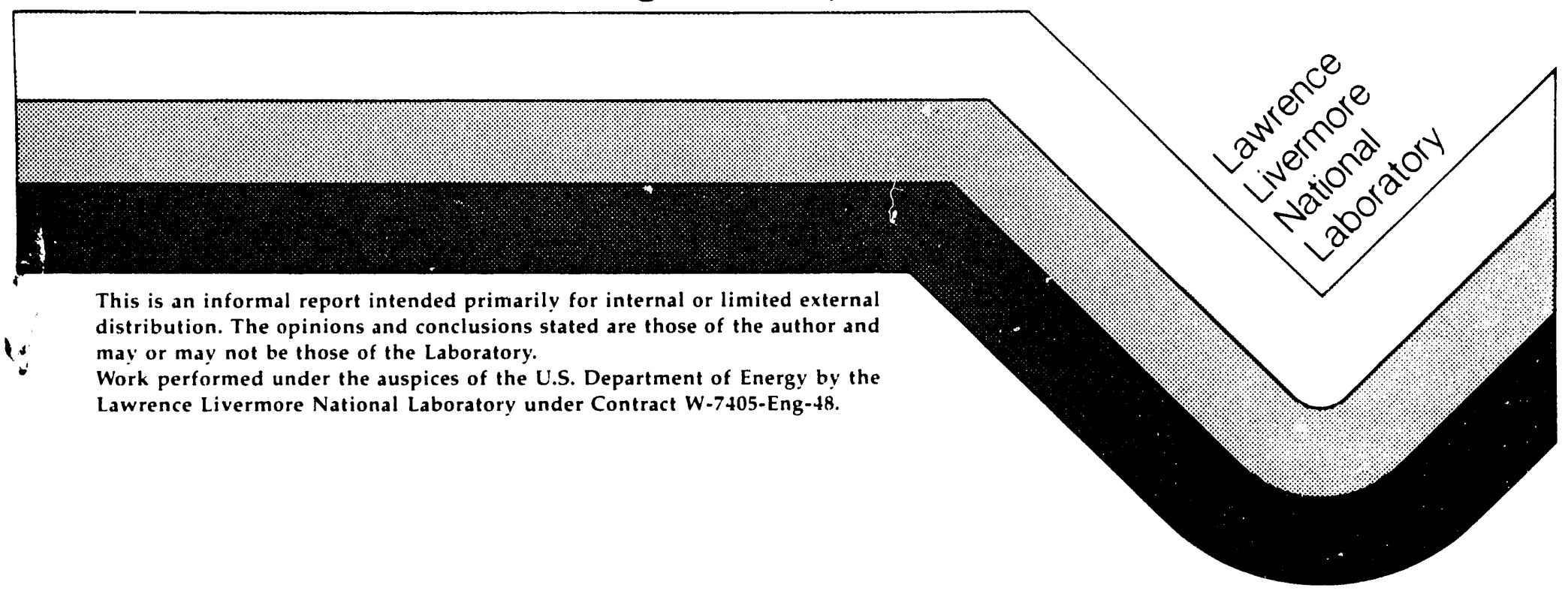




\section{DISCLAIMER}

This document was prepared as an account of work sponsored by an agency of the Lnited States Government. Neither the Lnited States Govern rent nor the University of California nor any of their employees, makes any warranty, express or implied or assumes any legal liability or responsibility for the accuracy, completeness, or usefulness of any information, apparatus, product, or process disclosed, or represents that its use would not infringe privately own rights. Reference herein to any specific commercial products, process, or service by trad, name, trademark, manufacturer, or otherwise, does not necessarily constitute or imply its endorsement, recommendatior, or favoring by the United States Government or the Lniversity of California. The view's and opinions of authors expressed herein do not necessarily state or reflect those of the United States Government or the University of California, and shall not be used for advertising or product endorsement purposes.

This report has been reproduced directly from the best available copy.

Available to DOE and DOE contractors from the Office of Scientific and Technical Information P.O. Box 62, Oak Ridge, TN 37831

Prices available from (615) 576-8401, FTS 626-8401

Available to the public from the National Technical Information Service

U.S. Department of Commerce

5285 Port Roval Rd.,

Springfield, VA 22161 
UCRL-ID--107884

I DE92 002940

\title{
DYNA3D ANALYSIS OF THE DT-20 SHIPPING CONTAINER
}

\author{
R. W. Logan \\ S. C. Lovejoy \\ NEED - AMG
}

\begin{abstract}
A DYNA3D model of the DT-20 shipping container was constructed. Impact onto a rigid steel surface at a velocity of $44 \mathrm{ft} / \mathrm{sec}$ ( $30 \mathrm{foot}$ gravity drop) was studied. The orientation of most interest was a side-drop, but end and corner drops were also studied briefly. The assembly for the baseline side impact contained a $150 \mathrm{lb}$. payload. During this drop, the outer drum sustains plastic strains of up to 0.15 , with most of the deformation near the rim. The plywood/Celotex packing is crushed about 3 inches. The inner sealed can sees significant stresses, but barely reaches the onset of yielding in some local areas. Based on hand calculations, the bolts joining the can halves could see stresses near $50 \mathrm{ksi}$. It is felt that overall, the container should survive this drop. However, detailed modeling of the rim closure and the center bolted joint was not possible due to time constraints. Furthermore, better material models and properties are needed for the Celotex, plywood, and honeycomb in particular.
\end{abstract}

\section{Introduction / Model Development}

The overall design of the DT-20 container is shown in Fig. 1. A stainless steel 146 gal. drum forms the outer shell. Inside, the packing consists of alternating annular rings of Celotex and 3/8" plywood. This provides thermal and shock insulation for the inner stainless can (Fig. 2). The can is elliptical at both ends, representing a change írom the design in Fig. 1. At each end, a honeycomb with 500psi initial crush and 150psi subsequent crush is used. The upper and lower halves of this can are joined by a flange that uses $181 / 2 \times 13$ bolts (Fig. 3 ). Inside the can are the payload and support structure shown in Fig. 4.

An overall view of the DYNA3D side-drop model is shown in Fig. 5. The Celotex packing is omitted in these and many other plots for clarity. The outer drum, plywood, and inner can are shown in Fig. 6, with the Celotex packing shown in Fig. 7. All parts are merged, except for the following slide surfaces. These used the sliding with voids model and a friction coefficient of 0.300 . Obviously, the drum to impact surface is modeled. In addition, the end Celotex plates are free to slide

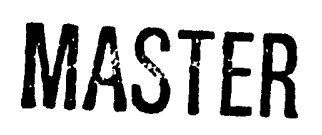


within the drum. The end plywood plates are merged to these Celotex plates. The Celotex annular rings are modeled as a single part, with the plywood rings merged in. This assembly is again free to slide or rattle against the outer drum and inner can. The can is shown in Fig. 8 It is free to rattle inside the Celotex/plywood packing. The 'discrete nodes impacting' feature was used to model sliding on the ends of the pipe portion. Inside the can is the payload and support structure (Fig. 9). The honeycomb ends are merged to the inner can of Fig. 8, but slide against the outer aluminum plates. All four plates slide against the can. The payload is merged to the two inner plates. Joining the plates are beam elements representing the threaded rods. These are modeled as pinned ends rather than fixed ends, and thus their buckling strength may be lower than the real rods. This model contains a total of 22 slide surfaces, about 13000 nodes, and takes about 3 hours on the CrayYMP to run to 20 milliseconds. Components and their total weights in the model are shown in Table 1 below.

Table 1. Component Weights in the DT-20 DYNA3D Model

\begin{tabular}{|c|c|}
\hline Component & Weight (lbs) \\
\hline Stain!ess Drum & 179 \\
\hline Plywood & 29 \\
\hline Celotex & 163 \\
\hline Stainless Can & 244 \\
\hline Honeycomb & 29 \\
\hline Aluminum Plates & 121 \\
\hline Rods & 16 \\
\hline Payload & 150 \\
\hline TOTAL & 931 \\
\hline
\end{tabular}

\section{Celotex Properties}

Material properties for most of the model are fairly straightforward. One exception is the honeycomb, which is modeled as a 150psi crush 'Model 5' material. A better model is needed for the end and corner drops, but the honeycomb is not critical for the side drop. The major unknown involved good properties and a model for the Celotex packing. Uniaxial crush data from static tests was obtained from $Y-12$ and also from recent LLNL tests by R. Sanchez from ESD. Summary plots of Sanchez' data are shown in Figs. 10-12. With this information, parameters for Model 5 were developed or estimated. The pressure-volume behavior was taken from Fig. 12. Due to virtually nil Poisson strains during the uniaxial crush tests, the stress-strain behavior shown was converted to true stress-strain and then used directly as the pressure-volume zrushing behavior. Note that the high-rate drop tower data is nearly twice as stiff as the static data (Fig. 12 vs. fig. 11). . The drop tower levels were used as they were felt to be close to the strain rates the actual container would see. 
From Fig. 10, an approximate bulk unloading modulus of 800000 psi was used. With the information available, it was impossible to separate a deviatoric yield component, so this was taken as a very small value (50 psi) with a slight $(0.1)$ linear pressure dependence.

\section{Results: Side-Drop, 150 Ib. Payload}

Figures 13-17 (a-d) show the results of the DYNA3D side drop at $1 \mathrm{~ms}$ intervals. Most notable is the deformation of the drum, the crushing of the Celotex, and the crushing (actually buckling and breaking) of the plywood rings, resulting in a gap between the upper side of the can and the plywood rings. Fig. 18a shows the rigid body displacement (inches) of several materials versus time (seconds). The Celotex (A) decelerates more quickly and is stopped after about $9 \mathrm{~ms}$. The honeycomb (B), plates (C) and payload (D) move together and require about $11 \mathrm{~ms}$ to stop. The plot of velocity (inch/sec) vs. time (Fig. 18b) confirms these observations. Acceleration is plotted in G's ("smooth-2" in TAURUS used on data taken each $0.2 \mathrm{~ms}$ ) in Fig. 18c. The peak G's are clearly on the order of $200 \mathrm{G}$ 's.

Figure 19a shows the levels of effective plastic strain in the outer drum. Strains of about 20 percent maximum are observed. These are not dangerously high for annealed stainless, but what is significant is that they are concentrated around the rim of the drum, which must retain a good seal. From this model alone, we cannot predict whether the seal will be maintained. However, comparing the gross deformations with previous container drops, it appears likely that the seal would survive. Fig. 19b shows that the inner stainless can sees only the onset of plastic strain. Even in the areas where the payload support plates impact the can, there is only the onset of plasticity. In Fig. 19c, the extent of volumetric crushing (labelled plastic strain) is shown. The crushing exceeds a volumetric strain of -0.4 in some areas below the can. This means that the Celotex has been crushed to half (or less) of its original thickness. The plywood rings (Fig. 19d) have long since buckled and broken. In DYNA3D, the plywood is modelled as an elastic-plastic material, with a yield of $2 \mathrm{ksi}$ and a strain to 'failure' (Model-24) of 0.002 .

Essentially, this means that shortly after 'yield', the plywood breaks and loses all its strength.

In Figs. 20-21, longitudinal stresses in the inner can are shown in psi. This stress will tend to pull the bolted joint apart. The areas of maximum tension are about 10000 psi. With a can wall of .190", and $181 / 2 \times 13$ UNC bolts around the flange, the ratio of wall area to bolt area is calculated to be $11.9 / 2.55$, leading to bolt stresses of 47000 psi for a 10000 psi wall stress. This should be well within the load carrying capacity of the bolts.

It is clear from the above discussion that although this impact appears survivable, more detailed properties and modeling would allow additional certainty. There is little sense in developing a detailed closure ring or bolt flange model until we have a more accurate loading available. This will come only from additional testing on the Celotex, plywood, and possibly other materials. Data from accelerometers during actual drop tests would be of immense help. 


\section{Other Impact Conditions}

Two additional side impacts were run. The first had a payload of $300 \mathrm{lbs}$. Visually, the results are similar to the base impact. The only significant difference appears in the rigid body motion plots (Fig. 22a-C). The Celotex sees a rigid body displacement of about $1.6 \mathrm{inch}$, as in the base drop. However, the $300 \mathrm{lb}$. payload results in a displacement of 3.8" for the can and contents, as opposed to only 3.3" with the base payload. The accelerations are nearly the same in magnitude (as are the stresses in the bolt flange), but their duration is longer with the higher payload. This is significant, since it implies that if the drum closure and bolt flange survive the $150 \mathrm{lb}$. payload, they should also survive the $300 \mathrm{lb}$. payload.

An additional run was made to test the limits of the side-impact model. This run had a payload of $1500 \mathrm{lb}$. As expected, the Celotex stopped in about the same distance as before (see Fig. 23a-c), but the can and contents did not stop by the time the model was terminated due to mesh tangling. Given that the Celotex is nearly crushed at this point and the can still has about half its initial momentum, it is unlikely that the assembly would survive this drop.

An end-drop was run with the 150-lb. base payload, even though an actual test in this orientation is not currently planned. The goal was to test the robustness of the DYNA3D model in this type of impact. Figures 24a-27b show the results of this run at $1 \mathrm{~ms}$ intervals. There is a slight buckling of the outer drum, and crushing of the end plywood and Celotex. At a time of $13.5 \mathrm{~ms}$, the discrete-nodes-impacting slide surface between the outer end of the can and the plywood plate has become confused. As a result, these elements are becoming distorted and tangled (Fig. 27d) to a point where the time step essentially grinds to a halt. Fig. 28a shows the displacement along the container axis (z-direction). By the time the run was terminated, the Celotex $(A) \varepsilon$. nd honyecomb (B) have stopped and rebounded. However, the aluminum plates (C) and payload (D) are still moving downwards. This is because the threaded rods have buckled in the model (Fig. 27c). We suspect that in reality, the rods would behave as fixed-end rather than pinned-end beams, and this problem would likely be avoided. Velocities (in/sec) are shown in Fig. 28b and show a similar trend. Decelerations (in G's) are shown in Fig. 28c. Internally, these reach on the order of $150 \mathrm{G}$ 's. With the fixed-end beam model, the internal G levels might be somewhat higher. Figure 29a-d shows the damage to some of the components. The outer drum (a) sees only minimal plastic strain and would be expected to survive. The inner can (b) sees some plastic strain in the regions where the rods tie into the lower plate. Also, extremely high strains are indicated in the tangled mesh area along the bottom edge, but thes: are likely spurious due to the slide surface problems. The Celotex sees a high level of crushing on the end. The 'clear' areas have a volumetric strain of below -0.4. Under uniaxial conditions, this corresponds to a reduction in height of over $33 \%$. In the honeycomb (d), strains in the axial direction are plotted. These are small for the most part, but we must remember that the plates and payload have not yet stopped.

For similar purposes, we also ran a corner drop model. The orientation is such that a line from the container c.g. through the corner of the drum is perpendicular to the 
ground. Figures 30-34 (a-d) show the results of this run at $1 \mathrm{~ms}$ intervals. The gradual crushing of the drum and Celotex make this a relatively benign drop for the inner can and contents. However, buckling of the outer drum becomes so severe (Fig. 34c-d) that the drum-to-ground slide surface becomes toast, making the run rather meaningless at this point. Special measures will be needed to carry the run beyond this point and to completion... In any case, at a time of $18.5 \mathrm{~ms}$ (before the slide surface problems), the inner can and contents (Fig. 35a-b) seem to be intact. Displacements in the $y$-direction (radially outward from the drum center) and the $z$ direction (axis of the drum) are shown in Fig. 35c-d. These and the velocity plots (Fig. 36a-b) show that motion has almost stopped in the $y$-direction, but that the can and contents (B-D lines) are still moving in the z-direction at nearly half of the initial velocity. The $y$ and $z$ decelerations (Figs. $36 c-d, 37 a-b$ ) are quite low (under 100 G's), but again we must remember that the can contents have not been stopped yet. Regarding the deformations and survivability, Fig. 38a-d provides some insight. Plastic strains in the drum (Fig. 38a) show local regions with over 0.4 strain. These plots are shown at $t=16 \mathrm{~ms}$, before any major slide surface problems. It is open to debate as to whether the container rim seal would survive this level of deformation. The inner can (Fig. 38b) sees only minimal plastic strains. The corner of the Celotex (Fig. 38c) is highly crushed, accompanied by buckling and breaking of the lower plywood plate (Fig. 38d). Note that in the plywood, none of the plastic strains exceed 0.002 , since this value was specified as the failure cutoff. Figure 39 a-d shows the axial stresses in the inner can at times of $4,8,12$, and $16 \mathrm{~ms}$. The stresses reach local values of over 12000psi, but not at the bolt flange. Only a few thousand psi are observed there. From the side-drop bolt analysis, we would expect the bolted joint to survive this impact, assuming the stresses would not worsen if the run could be continued to completion.

\section{Conclusions and Future Needs}

The DYNA3D model of the DT-20 side drop indicates a probable survival with either the $150 \mathrm{lb}$. base payload or a $300 \mathrm{lb}$. payload. As stated above, there are three factors which contribute enough uncertainty that a 'probable' survival is as strong a statement as we can make. The first of these factors is the possible opening of the drum closure due to buckling of the ends of the drum. Without a separate model of the rim and closure assembly it is only possible to speculate. Crushing of the Celotex is quite severe, and although this does not affect the impact survivability, it could impair the container's subsequent fire resistance. The third uncertainty is the analysis of the bolted joint. Based on observed stresses in the can wall in the DYNA3D model, stresses in the bolts could be as high as 50000 psi. Additional loading components such as shear could put the stainless bolts on the verge of yielding. Further, a high desired safety factor could have the same effect. Again, analysis of a more detailed bolt joint model using stresses from the large DYNA3D model could help.

The end-drop model also indicates that the container should survive, although as stated above the run would not go to a complete stop due to mesh difficulties. Further development is needed on this model before any definitive statements are made. Similar conclusions hold for the corner-drop. However, in that case, it appears much more likely that the integrity of the outer drum closure could be lost. 
To resolve any of the above issues, more DYNA modeling will be required. This will necessitate better material properties and models, particularly for the Celotex and honeycomb. Accelerometer data from actual drop tests would help to verify the code's impact calculations. After these steps have been taken, it would be worthwhile to develop DYNA or NIKE models of the rim closure, bolt flange, or other local areas of the container.

Distribution:

D. S. Bretl

A. B. Copeland

B. E. Knapp

R. W. Logan (8)

R. R. Sandberg

D. A. Schauer

F. J. Tokarz (2)

J. J. West (1)

R. G. Whirley 

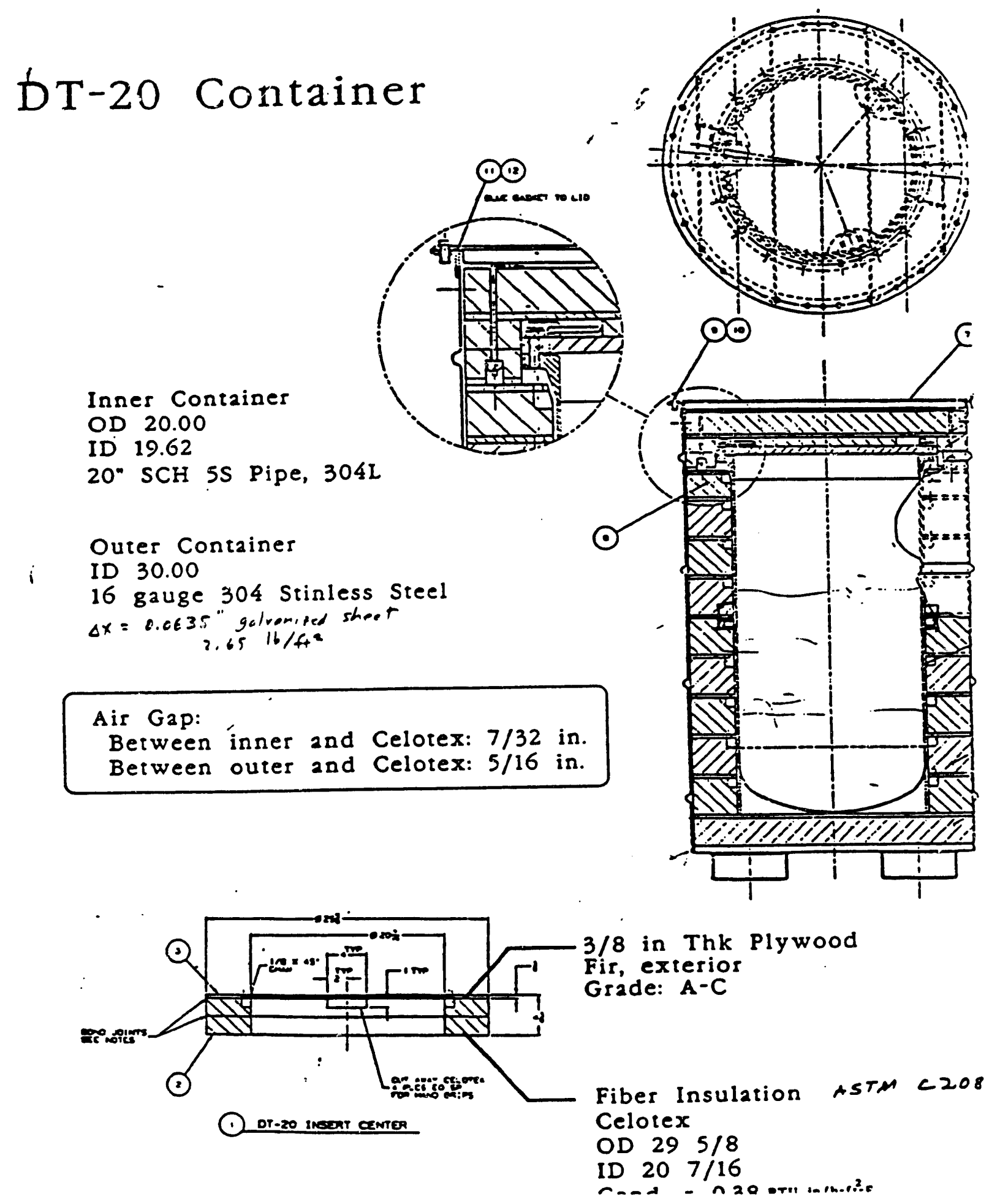

Figure 1. General sketch of the DT-20 container. 


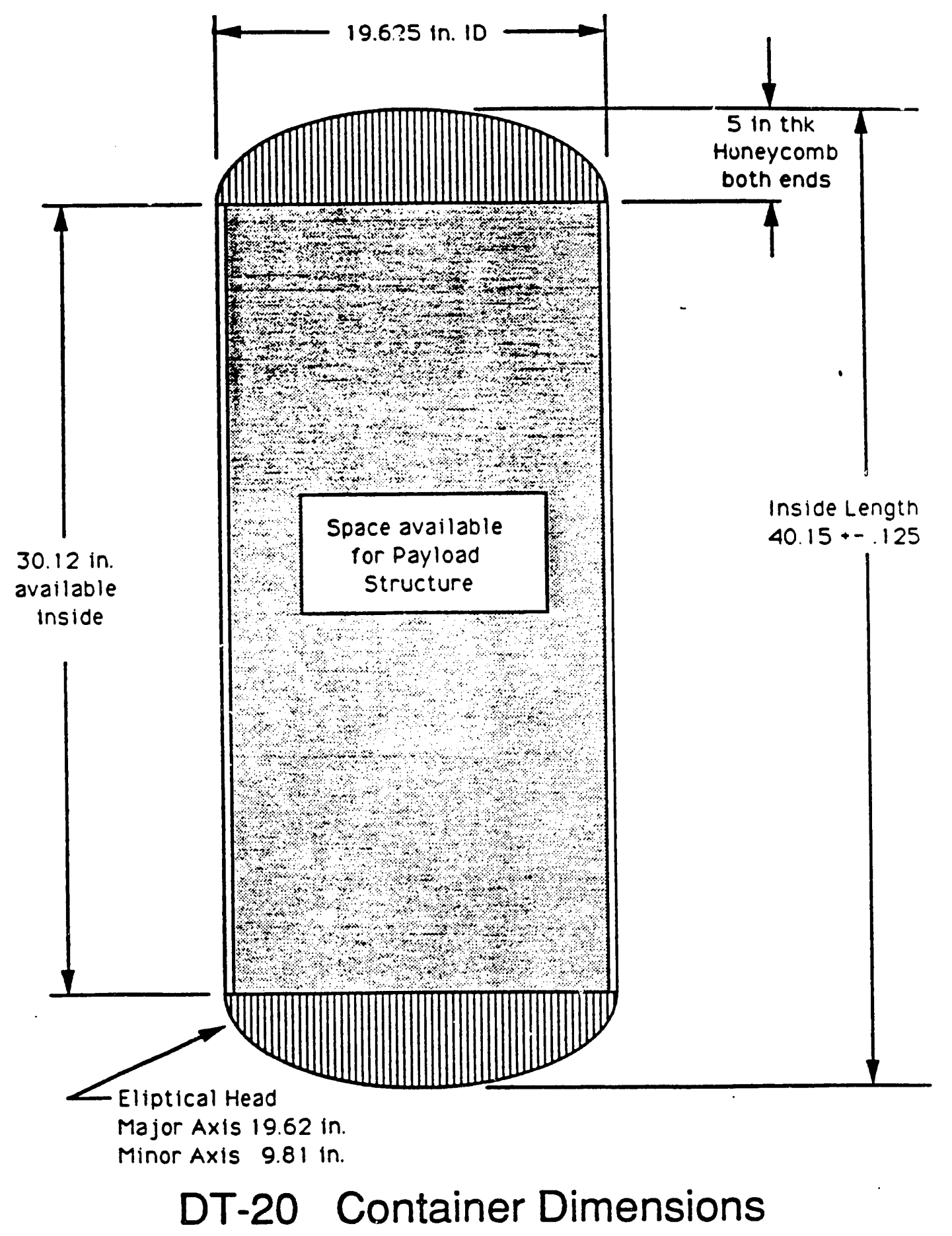

Figure 2. Outline of the stainless inner can. 


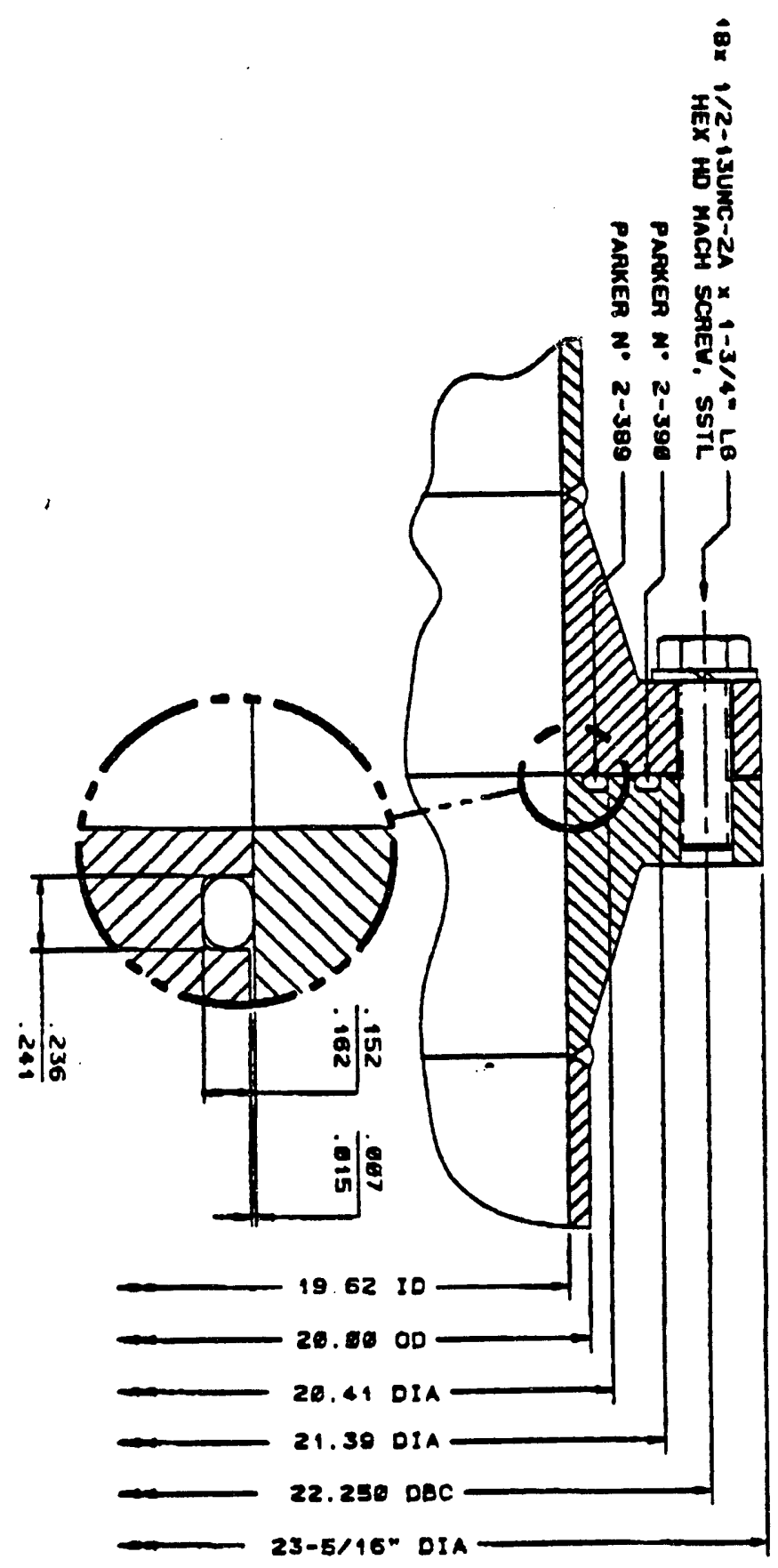

Figure 3. Bolted flange holding the two halves of the can, with O-ring seals. 


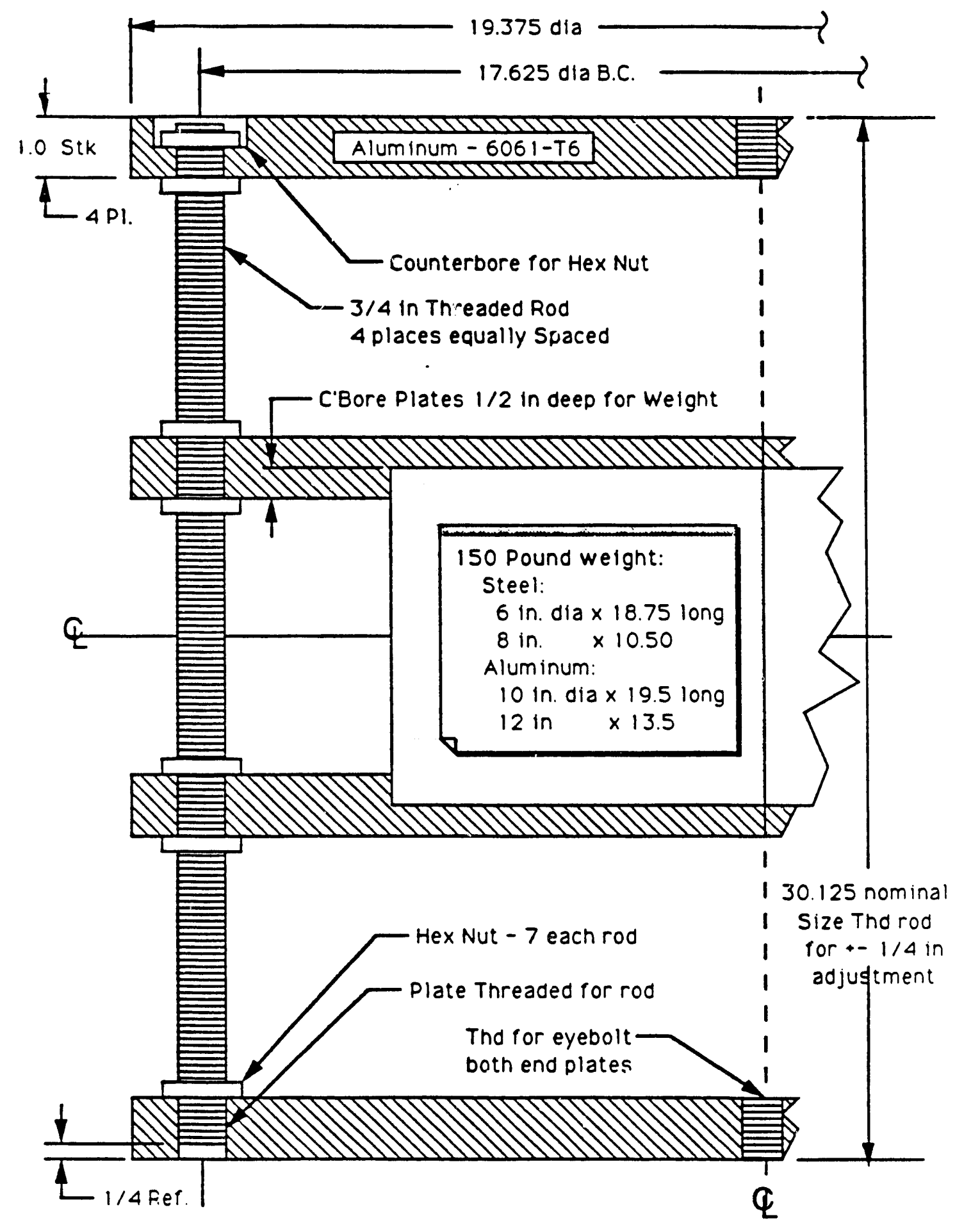

Figure 4. Inner can contents and payload area. 


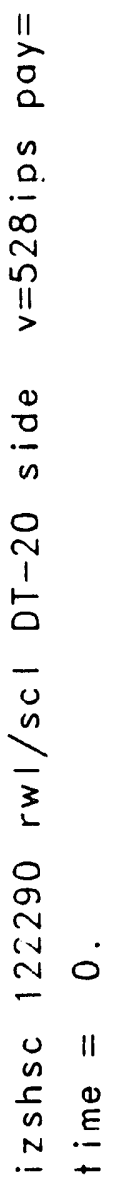

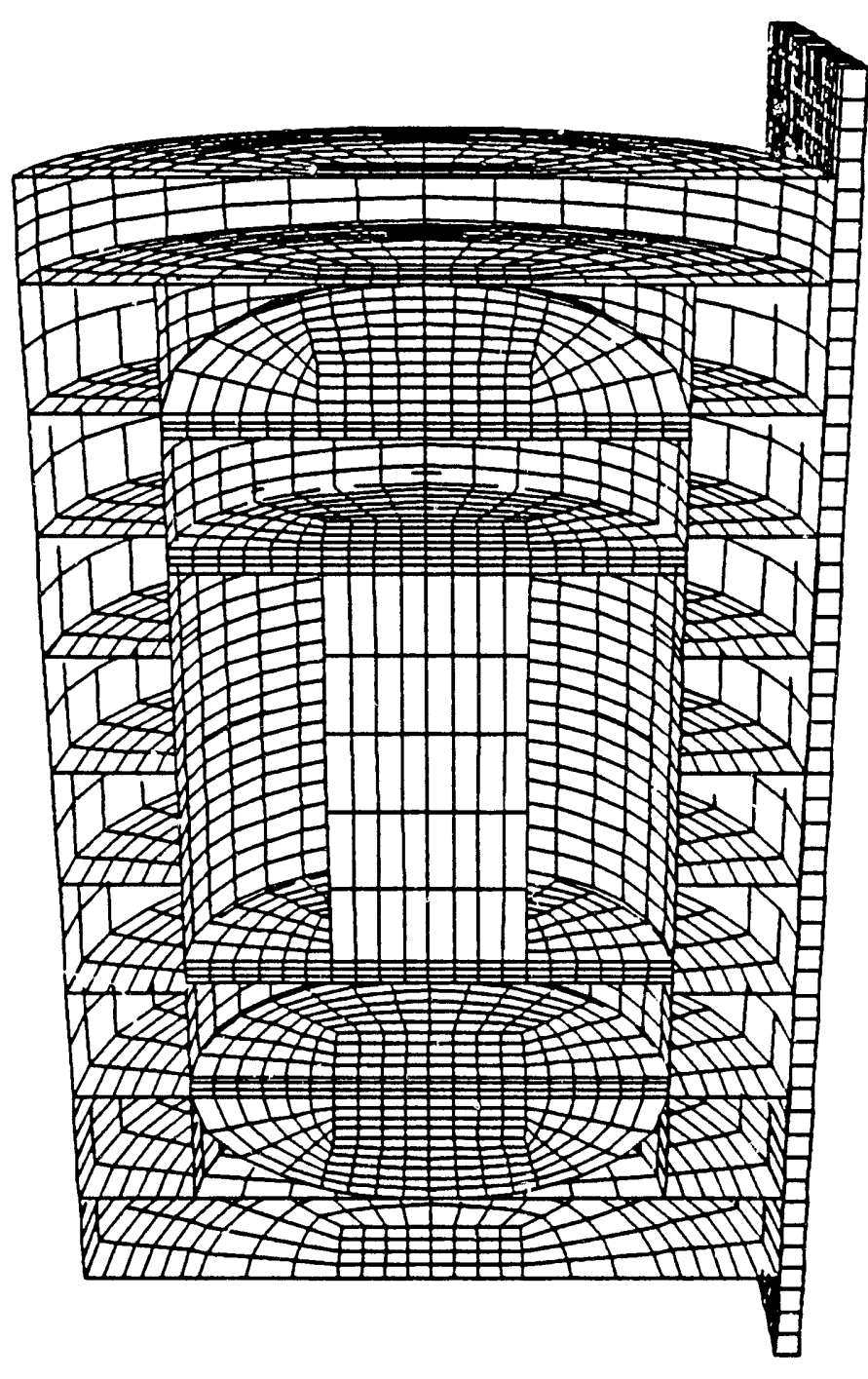

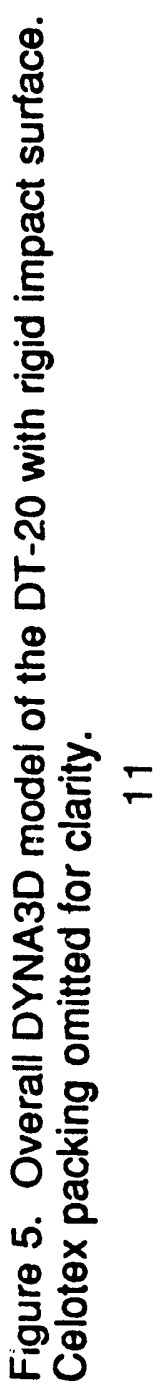



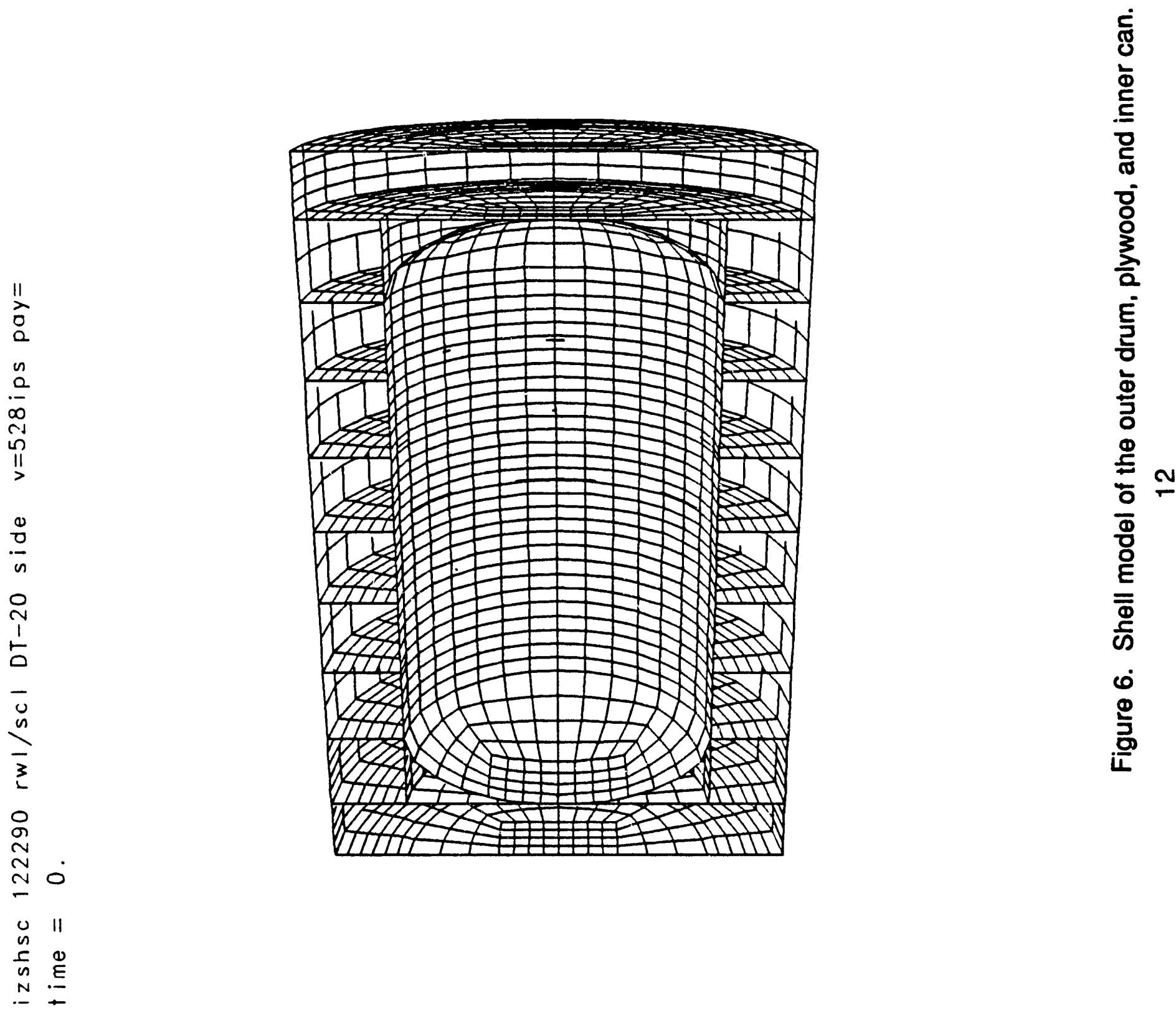


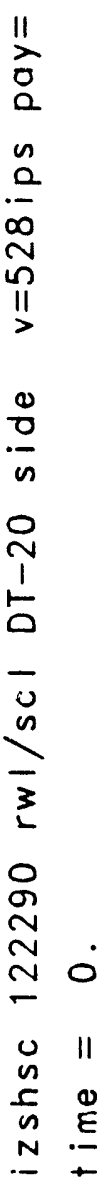
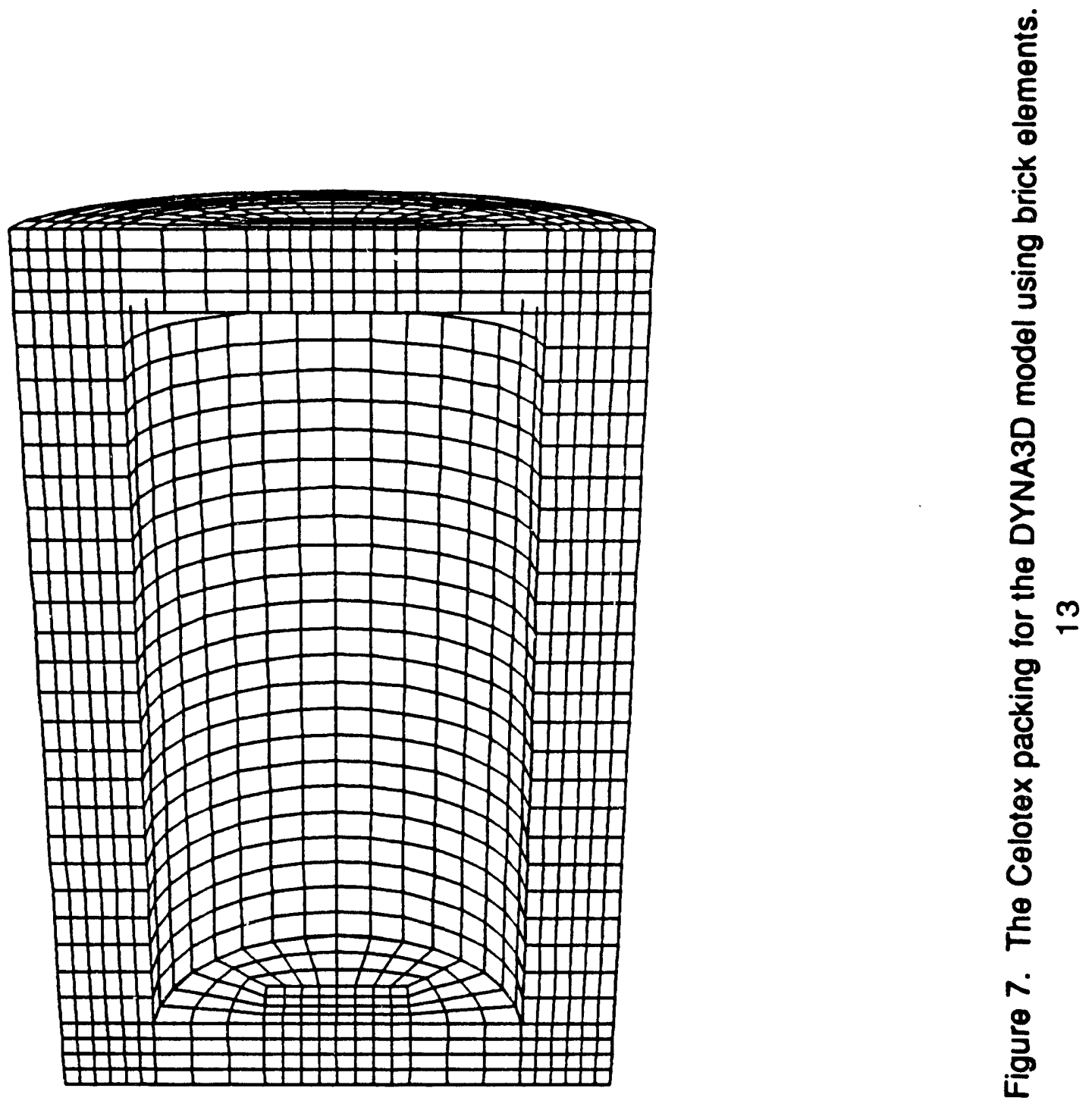


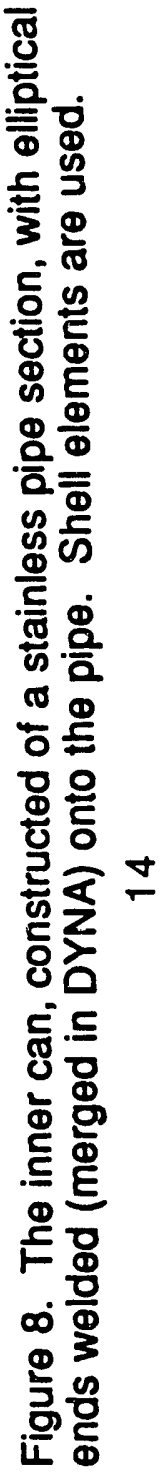



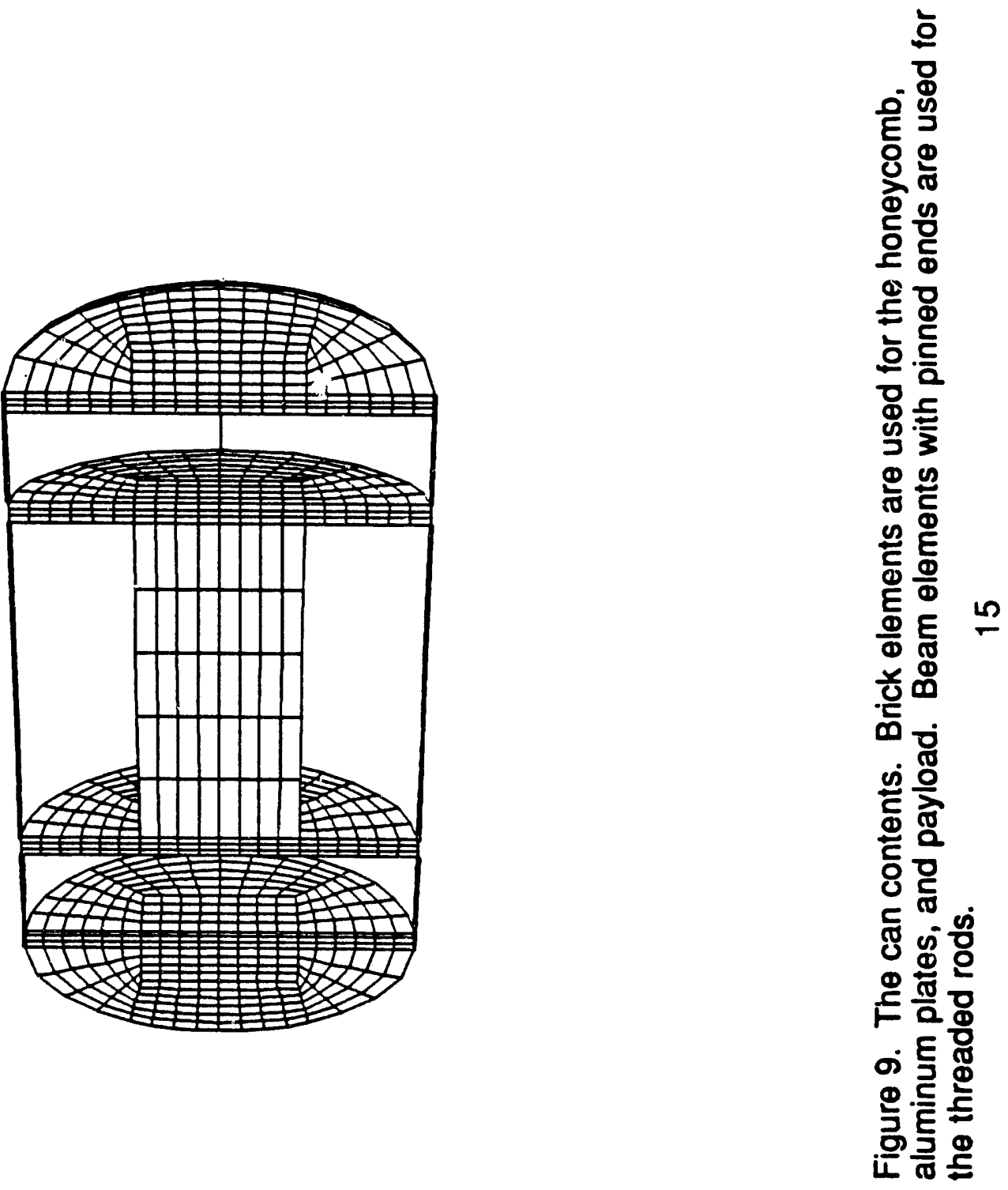


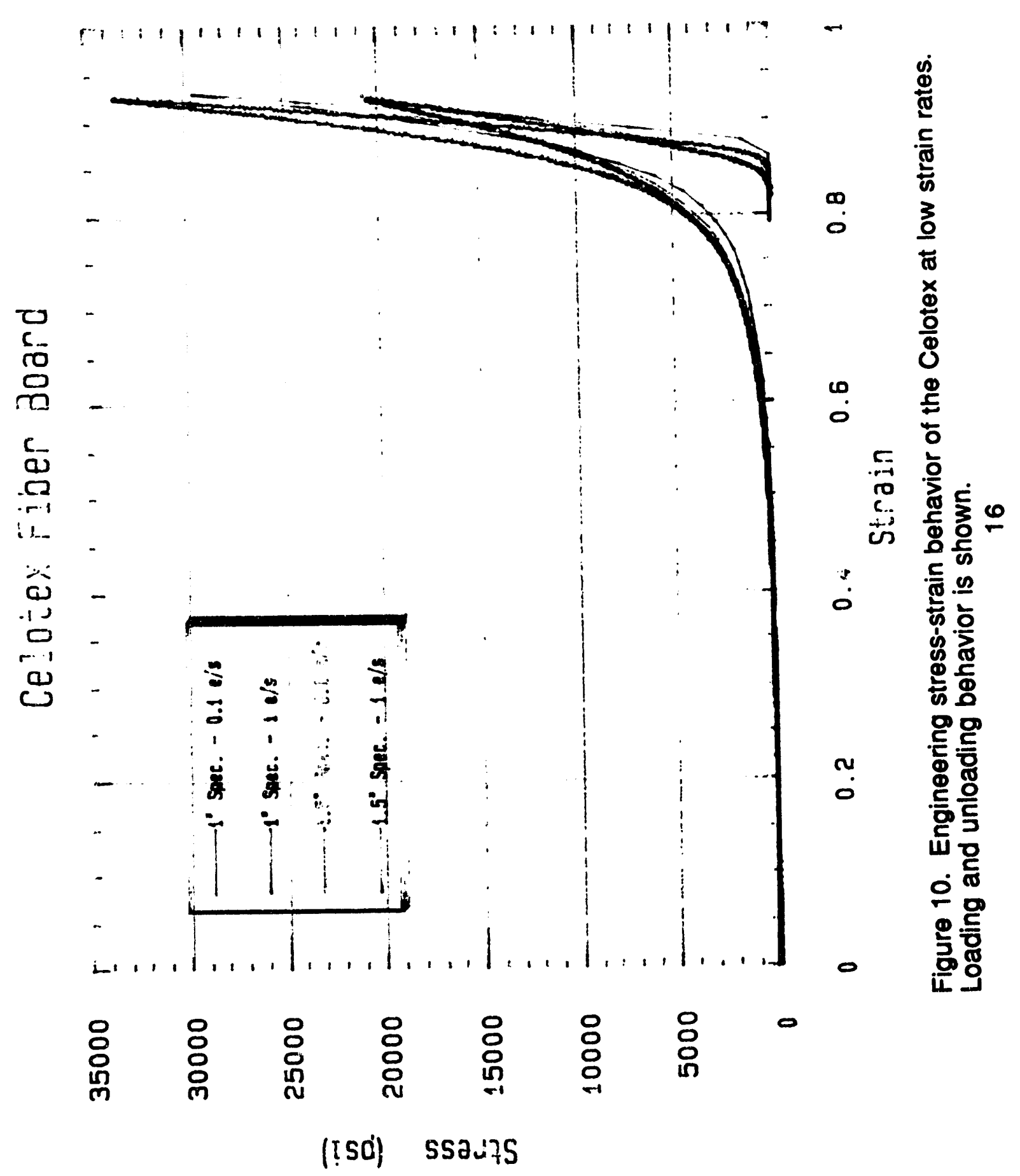




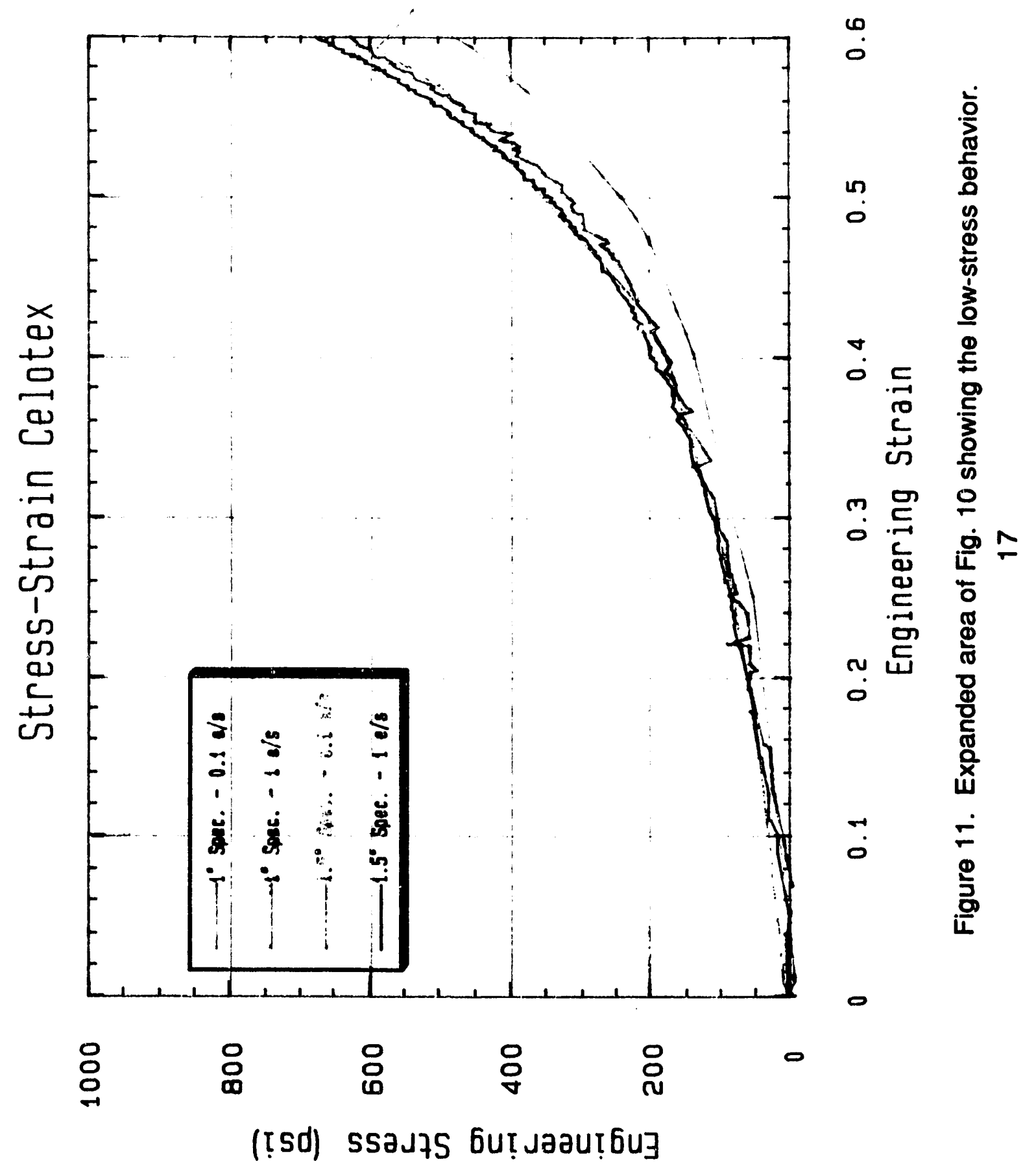




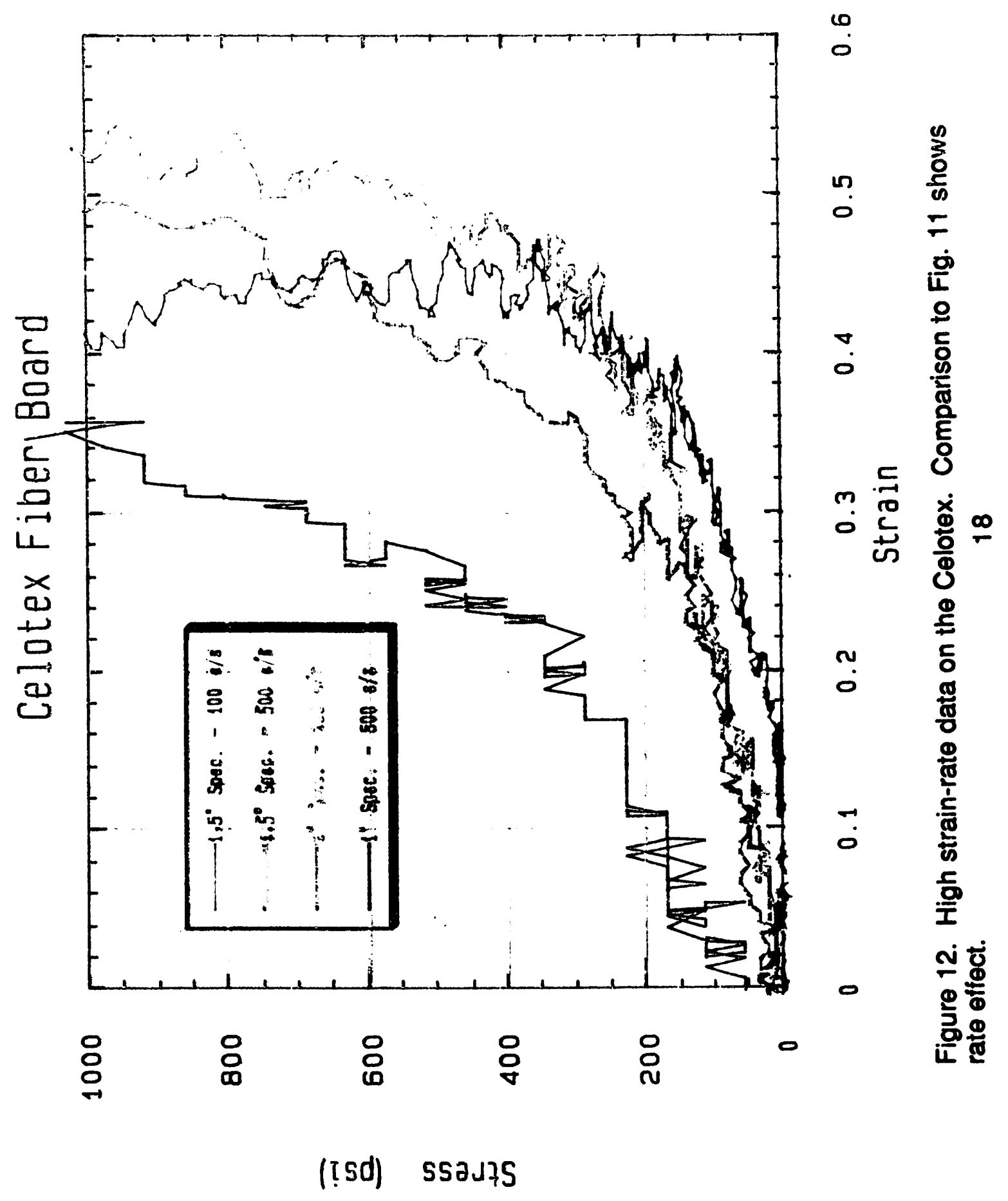



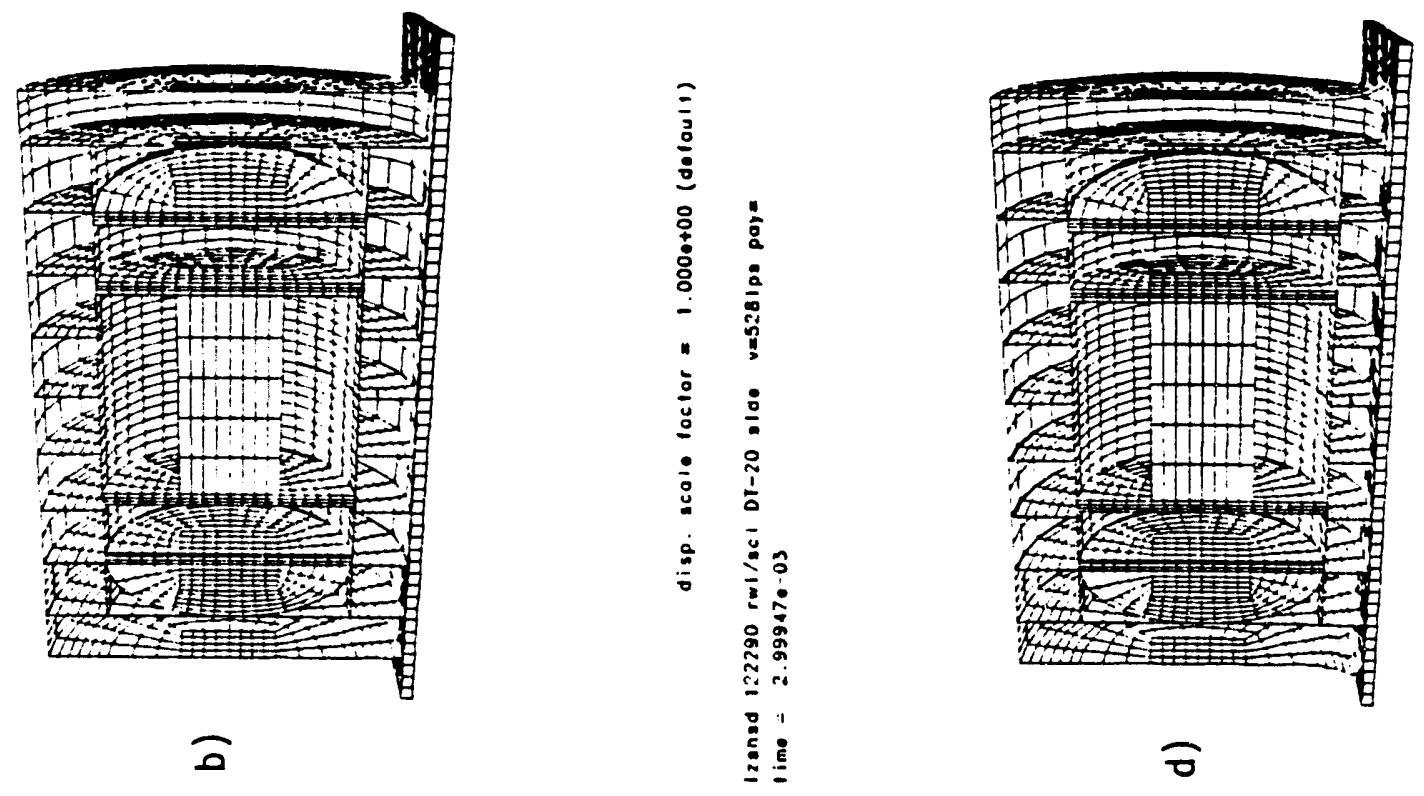

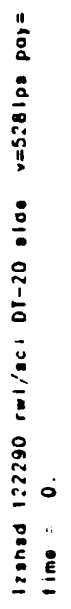

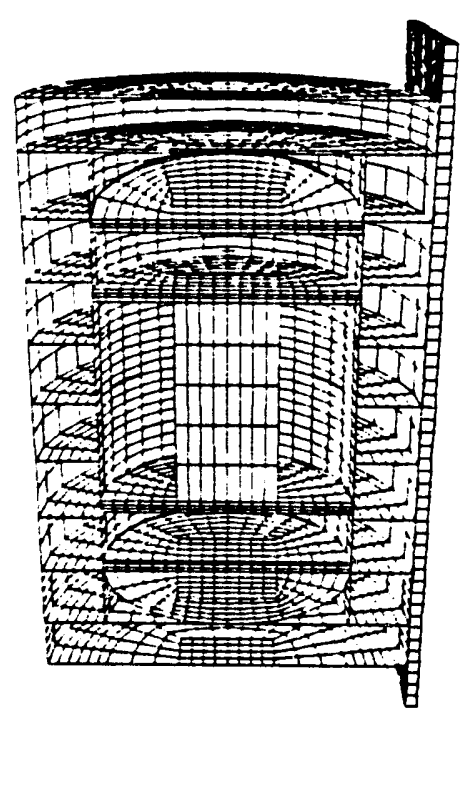

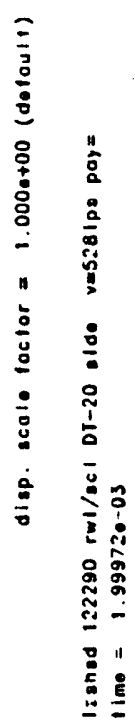
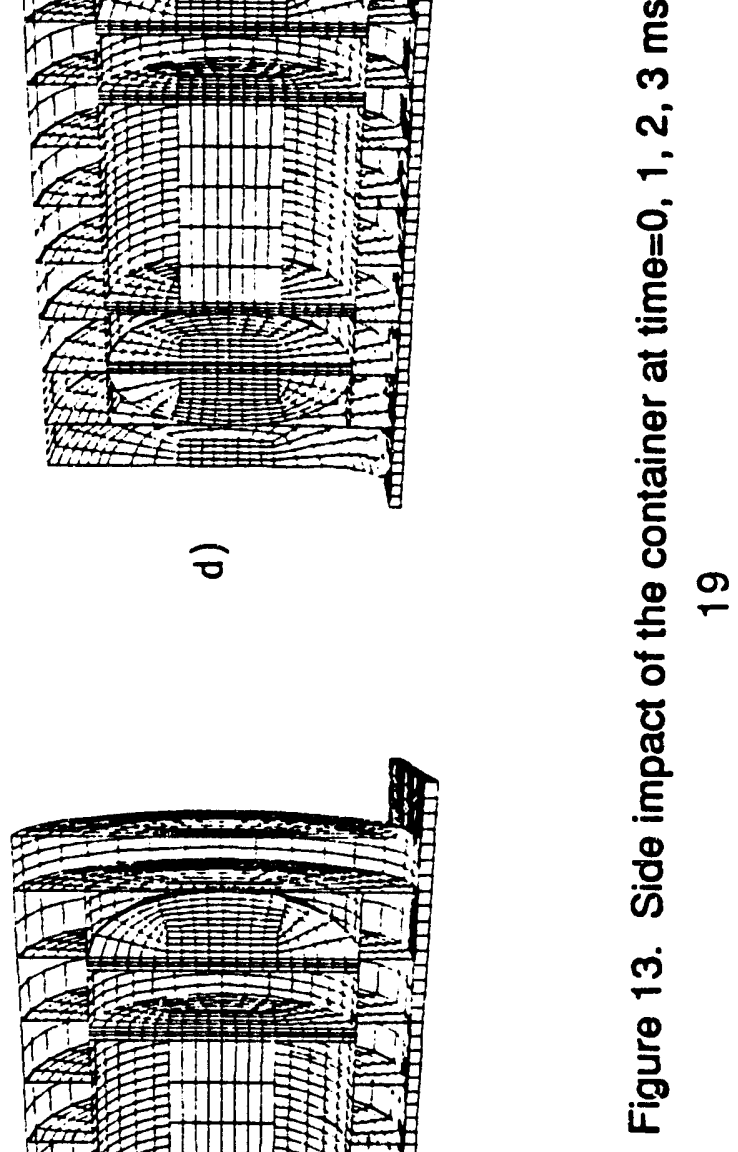

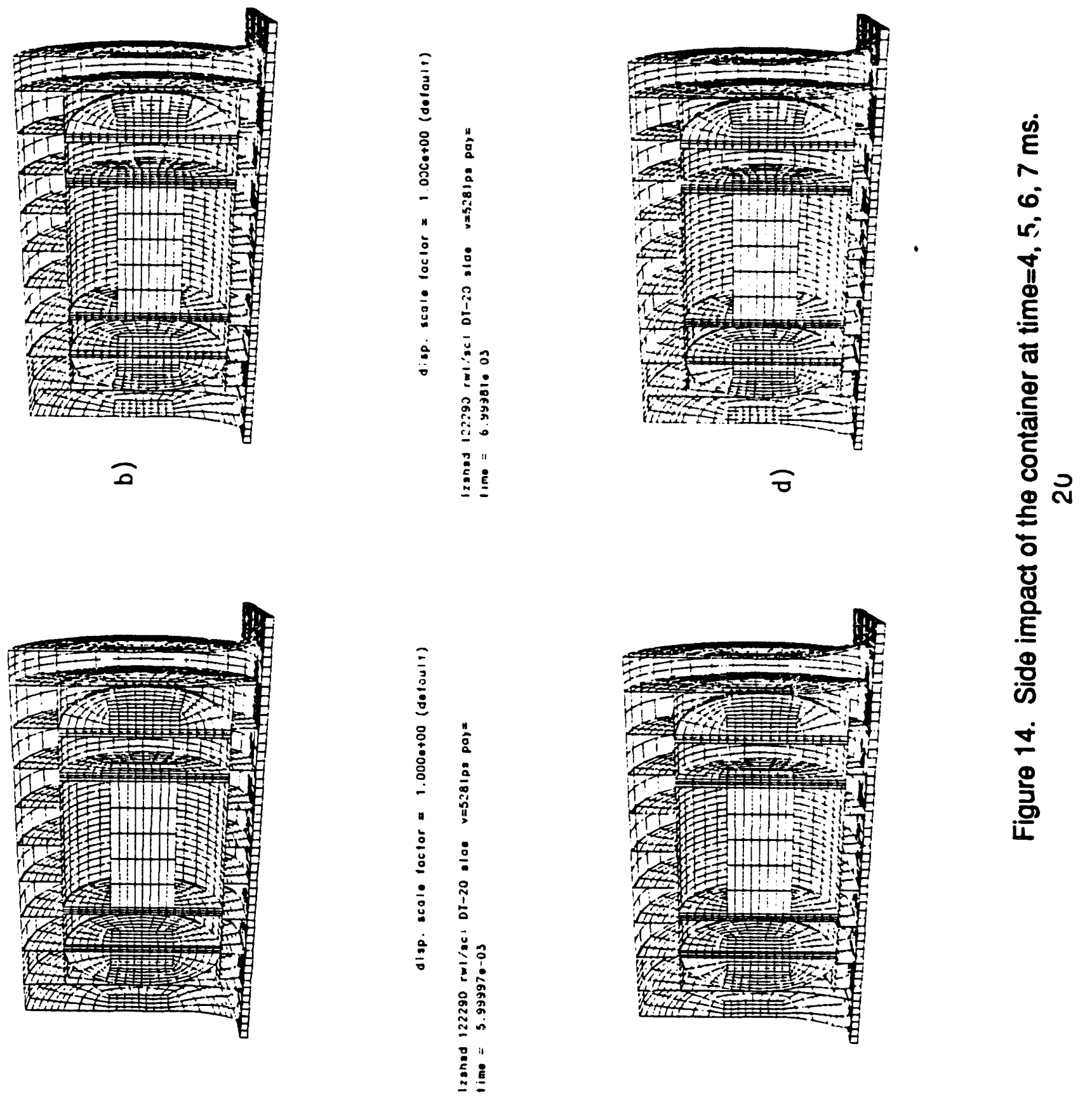

$\pi$
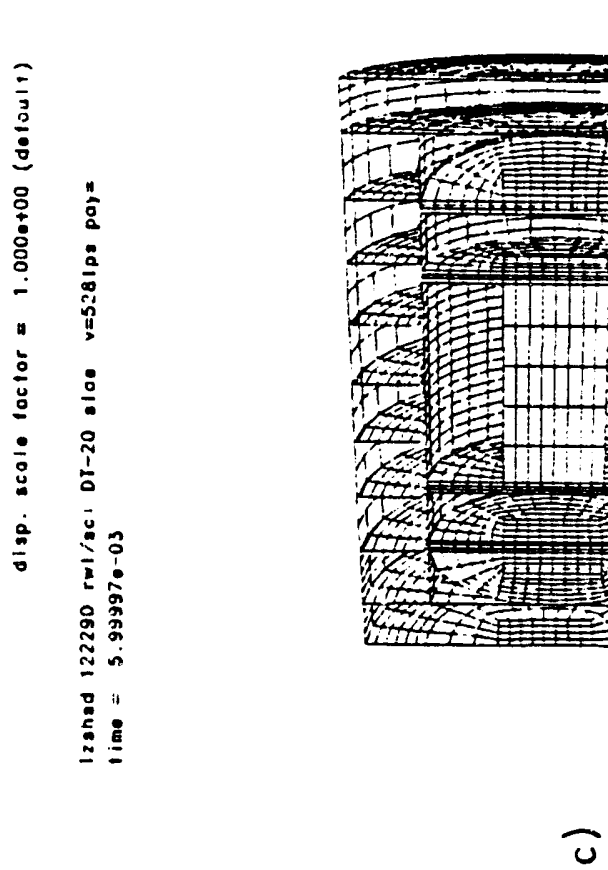

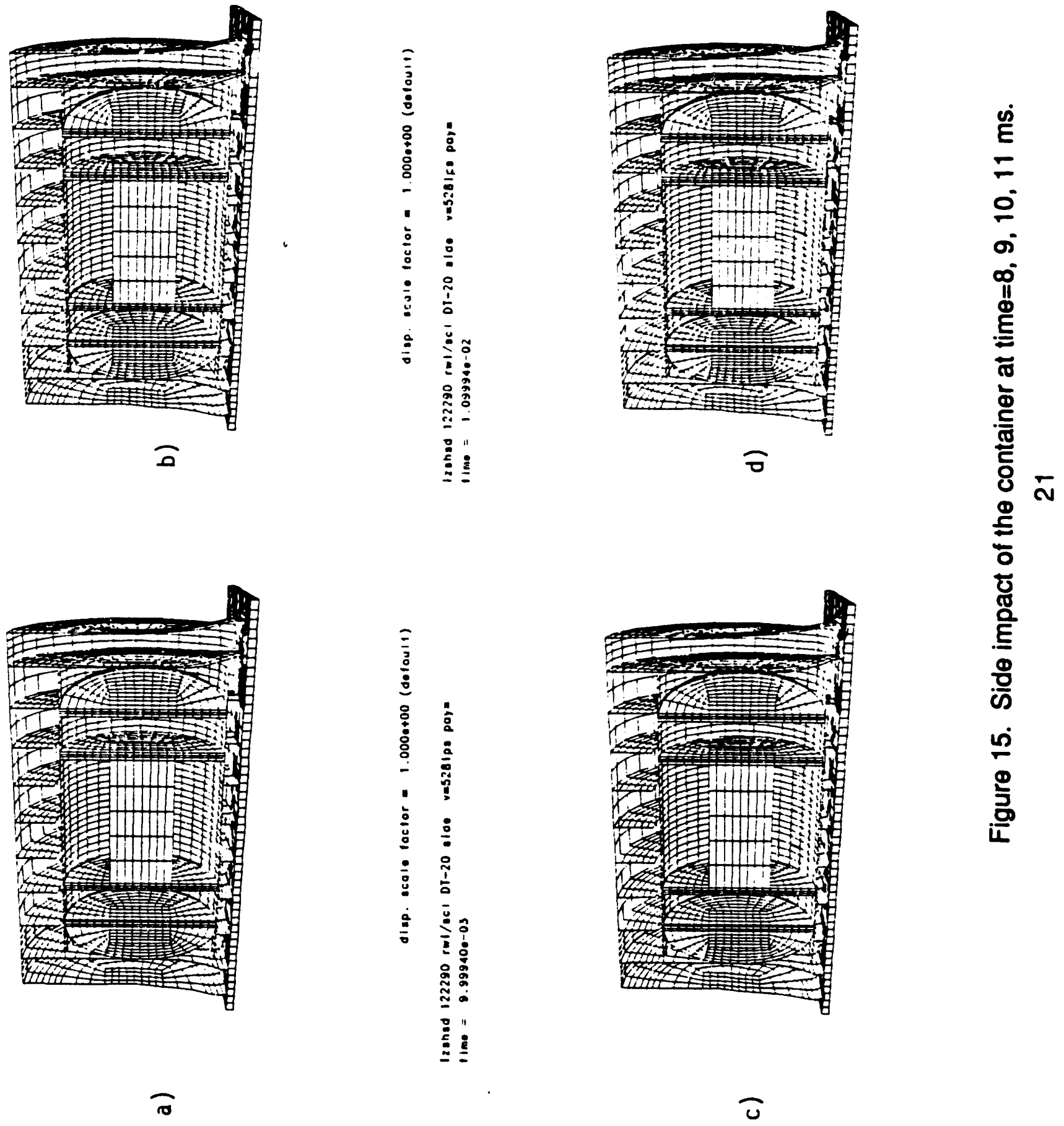

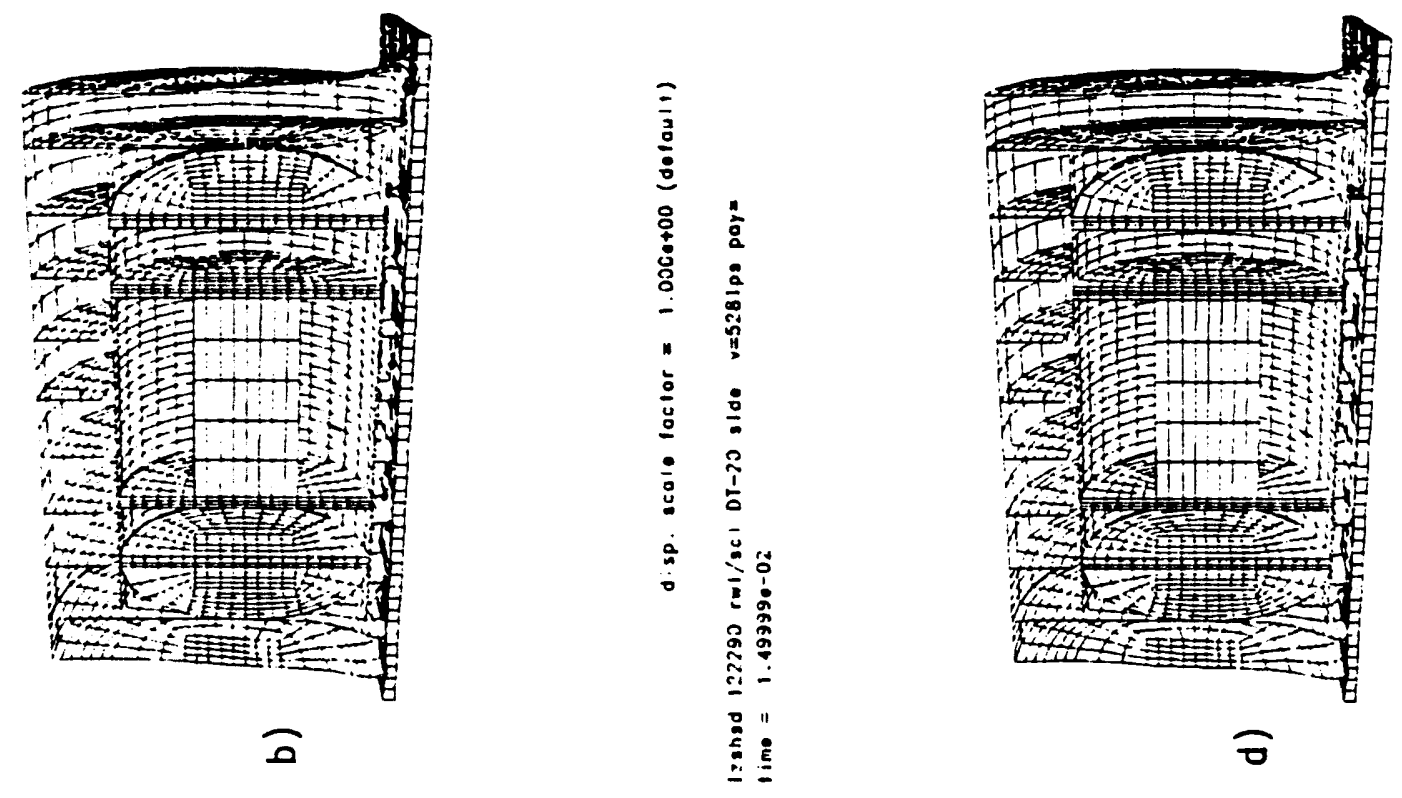

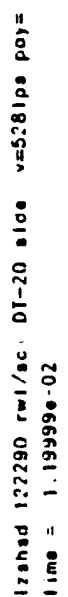
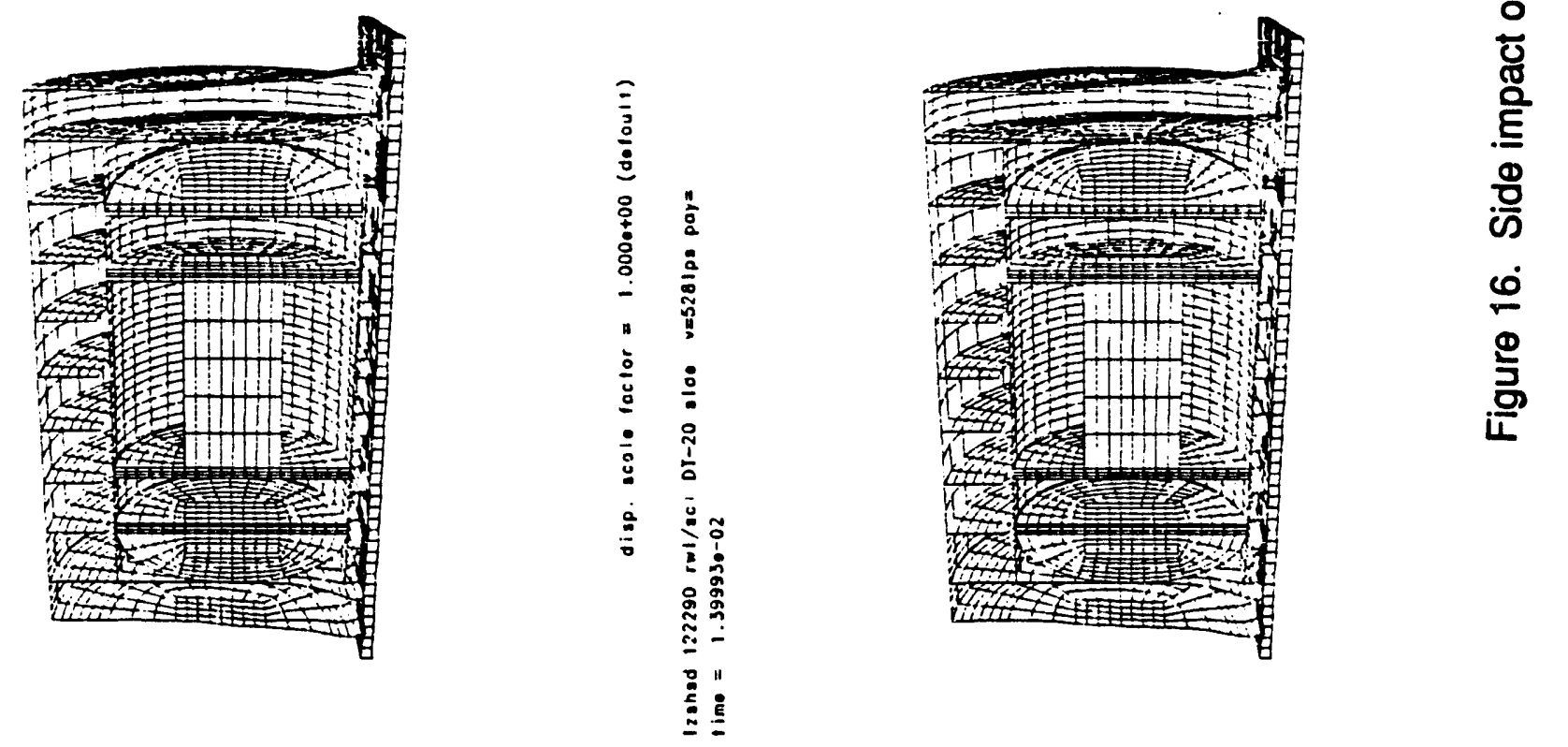

ช

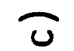



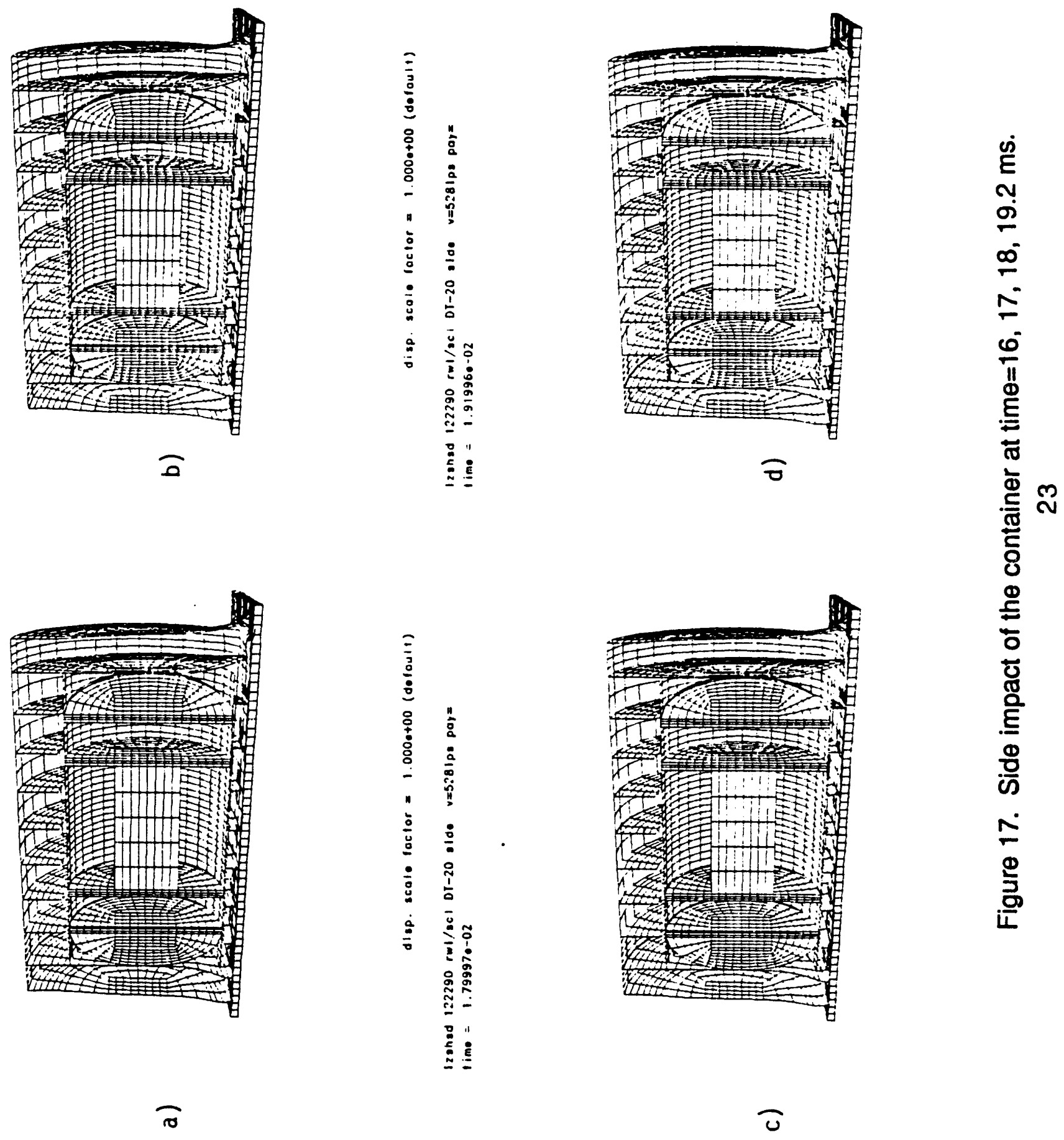

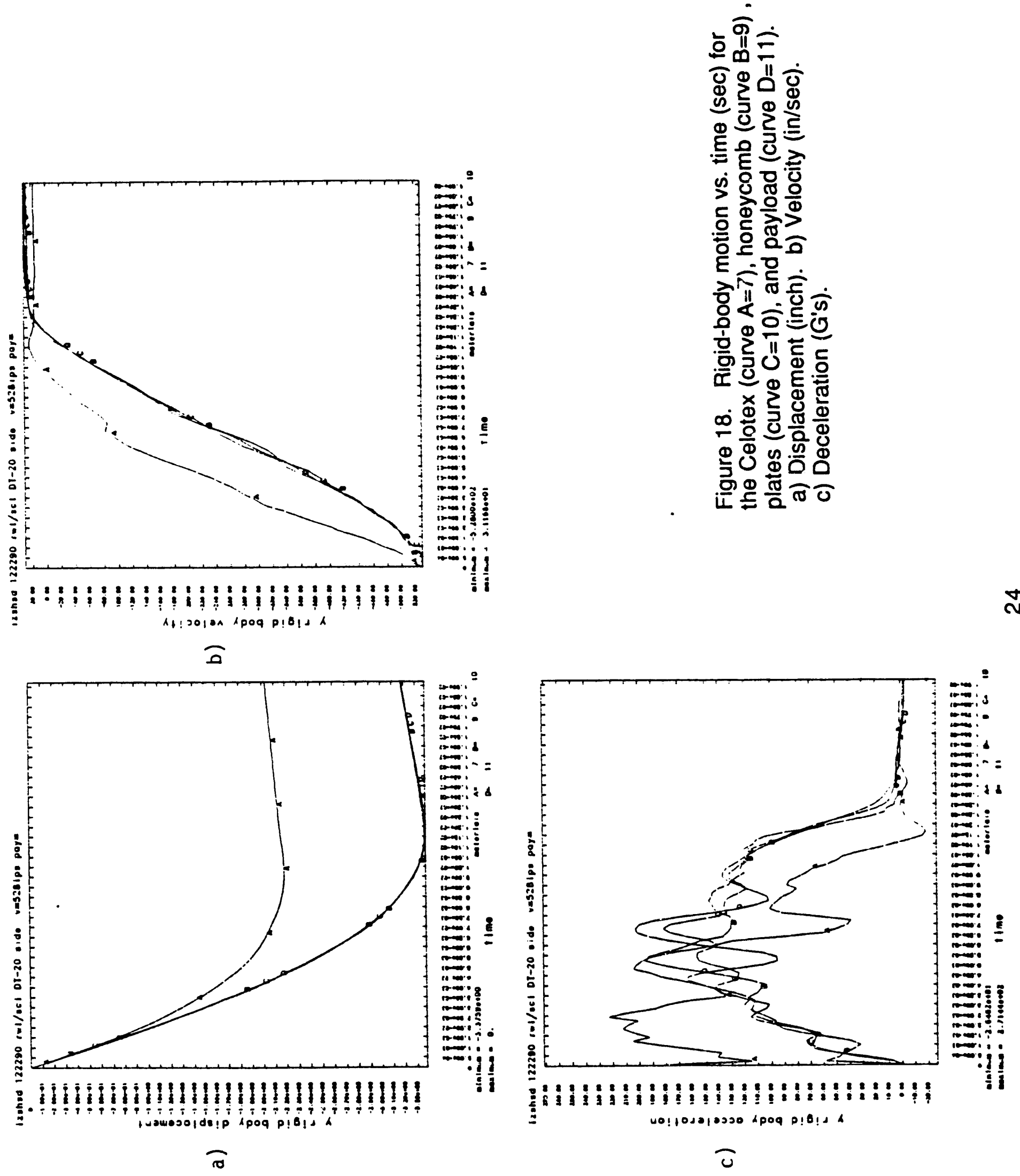


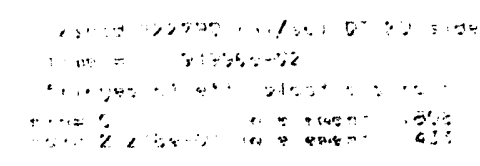

a)

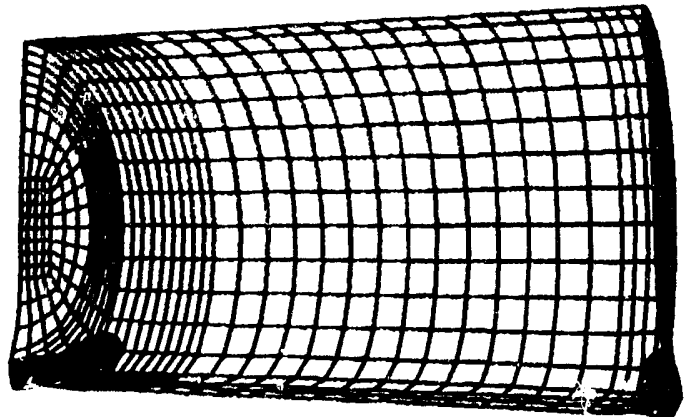

disp scalo factor $-1.0000+00$ (delaull)

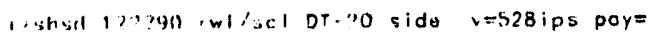

time :- 1.919960-012

irleges of ati plastic strair

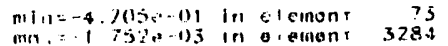

c)

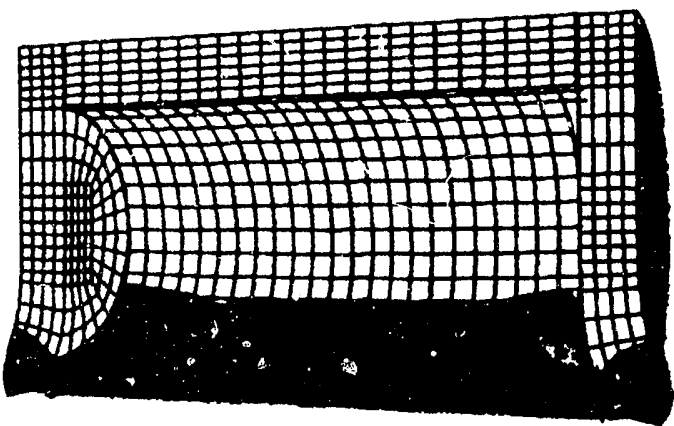

b)

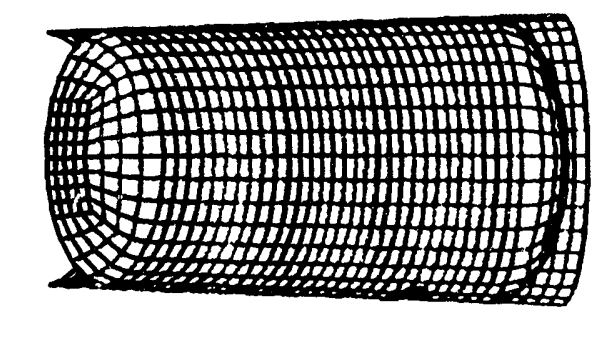

disp. scaln tastor 1 noveluo (desmull)

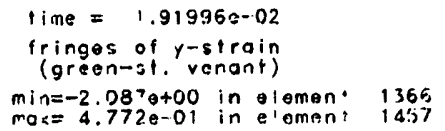

Holme 1.vele mexe-1,1 .

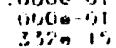

d)

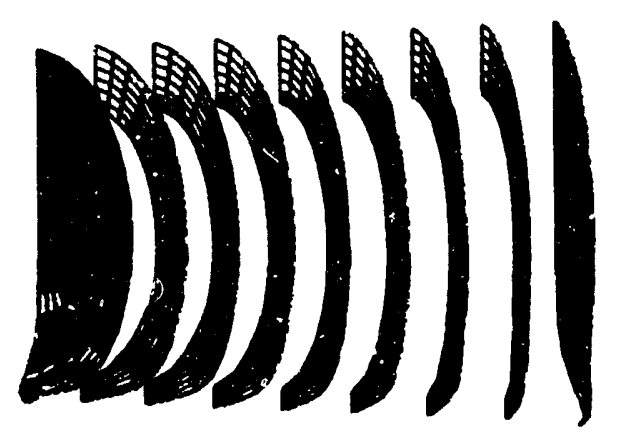

Figure 19. a) Plastic strain in the drum. at $19.2 \mathrm{~ms}$. b) Plastic strain in the can. c) Volumetric strain in the Celotex. d) $Y$-strain (crushing direction) in the plywood. 


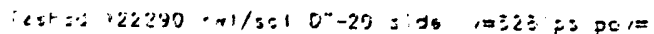

ine $=33 \% 3750-03$

irirgst ist z-zios:

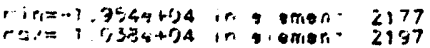

a)

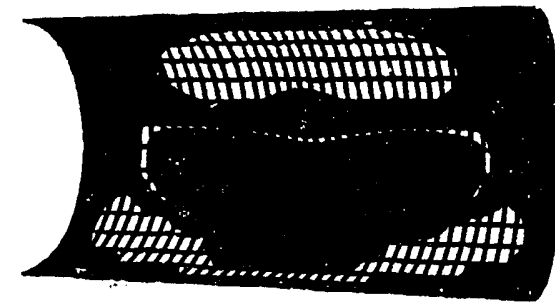

disp seale factor $=1.0000+00($ defoult $)$

i.shsol 122.990 iwl/sel ot 20 side va528ips poy=

lime $=$. 1999yo-02

firgas of z strass

min $=-8.5 i 20+03$ in omen. 2195

c)

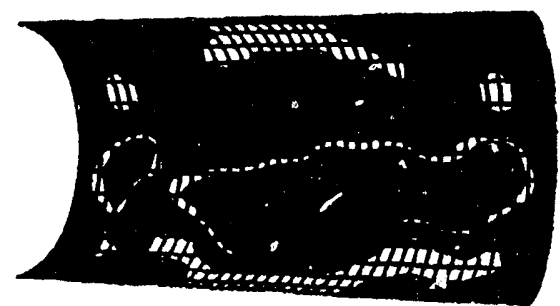

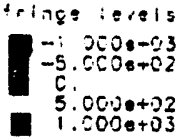

$$
i=
$$

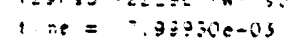

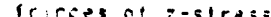

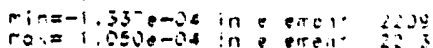

iccirtis

nowe+ion

Der $+6,3$ fringe levels
$-1.0000+03$
$-5.0000+02$
$0.0000+02$
$5.00000+03$
$1.0000+03$ b)

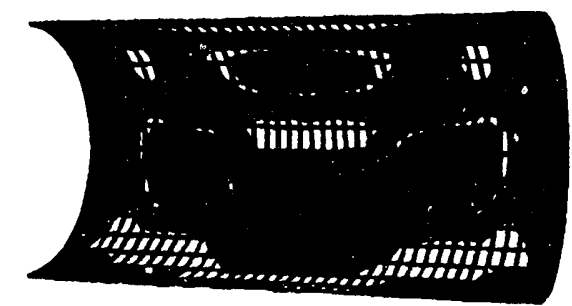

disp. scale factor- 1 bonarou (dotesult)

izshsd $122290 \mathrm{ewl} / \mathrm{sc}$ DT-20 side v S28ips poy-

time $=1.59996 \mathrm{e}-02$

fringes of z-stress

min $=-4.0040+03$ in elemen! 21.37
$\max =2.7080+03$ in lement 1976

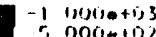

$1000+100\}$

Figure 20. Axial stresses in the can (psi), at $t=4,8,12$, and $16 \mathrm{~ms}$. 


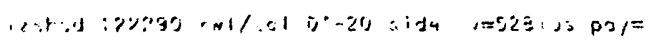

11 tises $=3.33^{2}, 76,4-03$

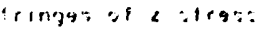

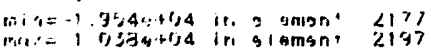

a)

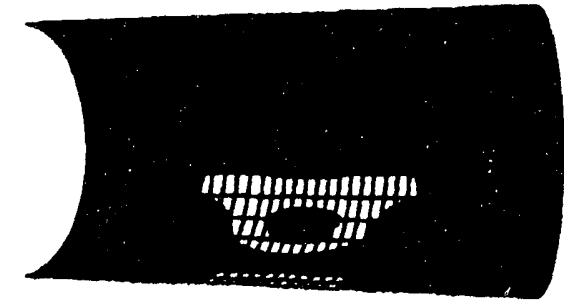

disp. scale factor $=1.0000+00($ default $)$

i / slisd 1\%2990 iwl/scl DT "O side v=528ips poy=

tine $=1.199490 .02$

tringas of z-stress

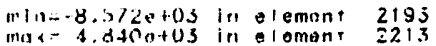

fringe isel:

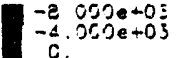

$4.0500+03$

- $8.300: 03$

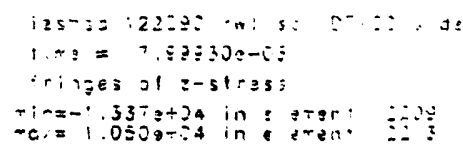

b)

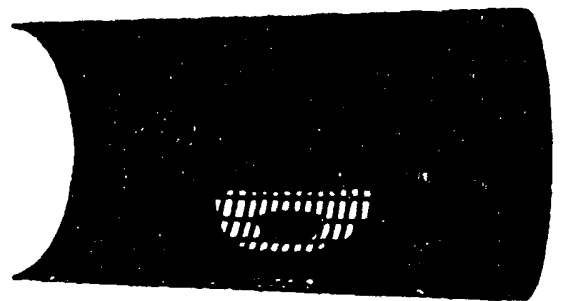

d sp. scalo factor $=100110+100($ detedult $)$

izshsd $122290 \mathrm{rwl} / \mathrm{scl}$ DT $-? 0$ sido v=528ifs pny=

time $=1.59996 \mathrm{c}-02$

fringes of z-stress

$\min =-4.004 e+05$ in siemont 2137
$\operatorname{mas}=2.7030+03$ in element 1976

$-8.0000+03$
$-4.0000+03$

$1.0000+03$

$1.0000+03$
$8.0000+03$ c)

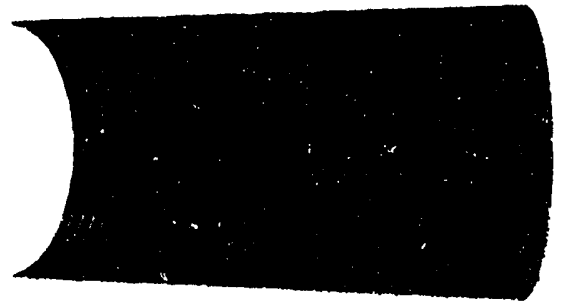

d)

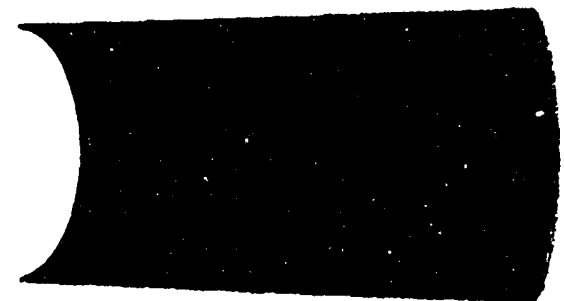

Figure 21. Axial stresses as in Fig. 20, but with expanded scale. 

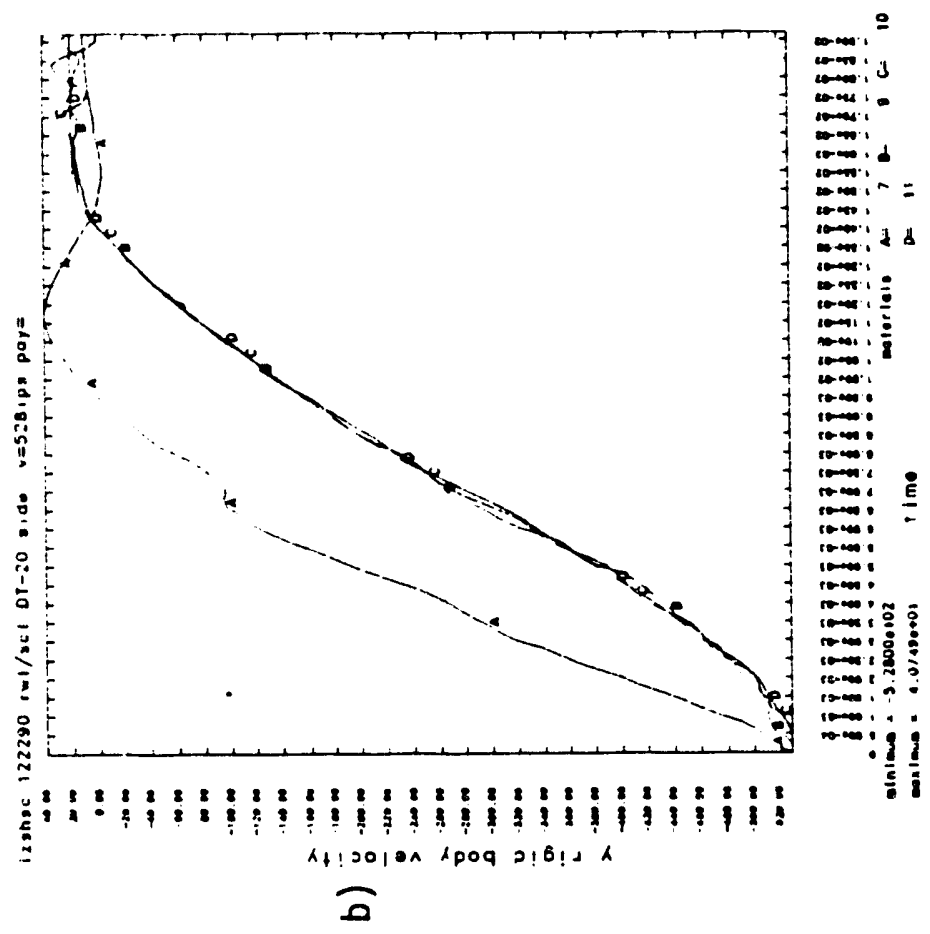

存

응

$\stackrel{\Phi}{=} \infty$

으 음

논

을 웛

ㅎํㅇ응

옹휴

또으

กู่

녹응요
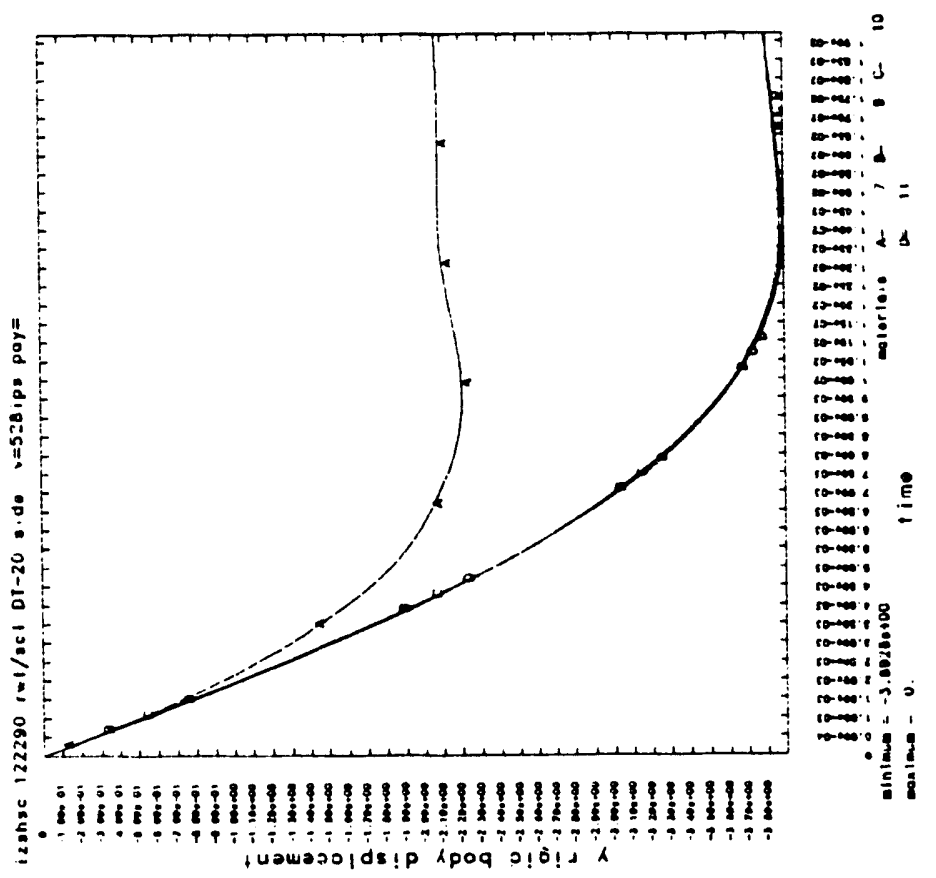

10
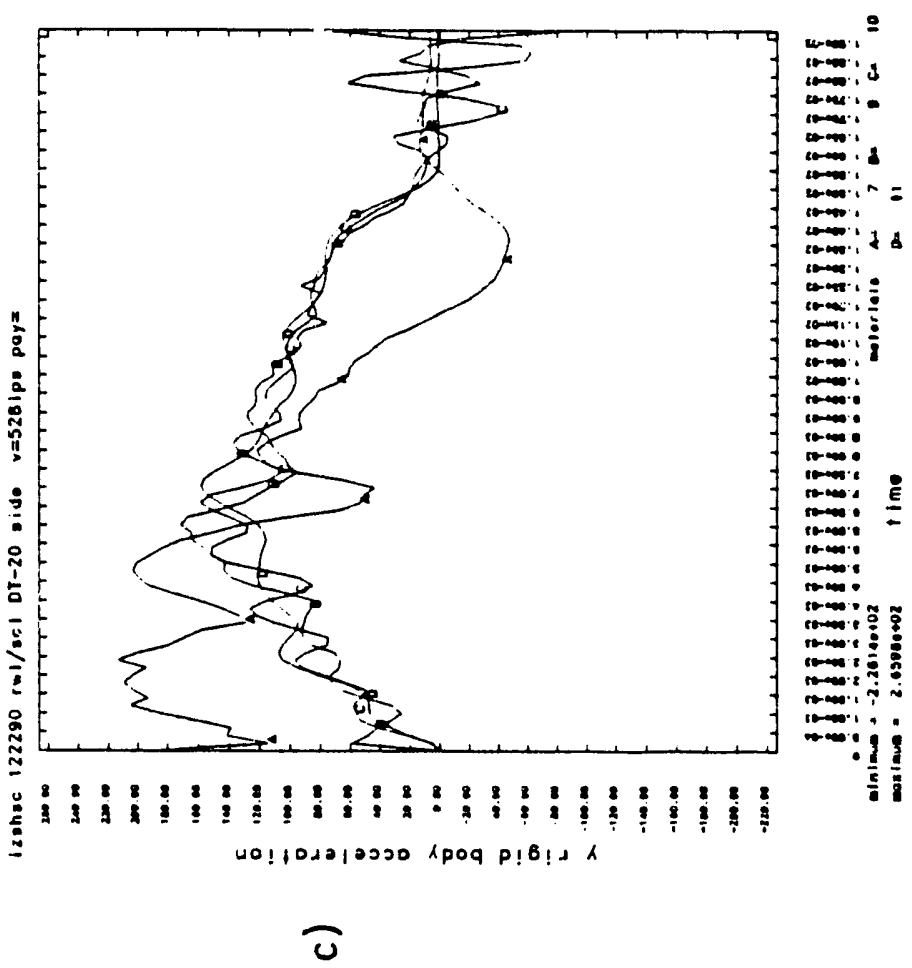


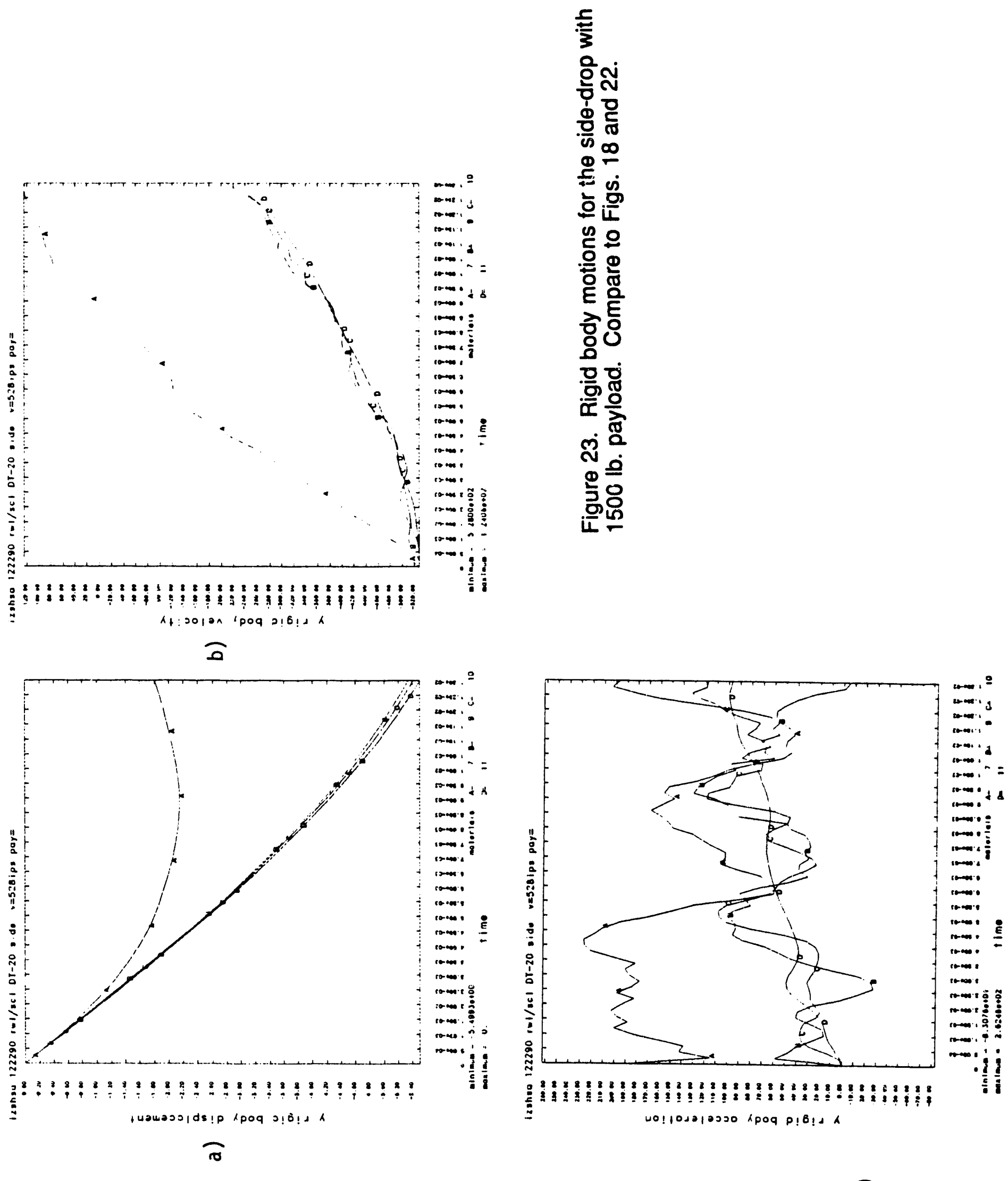



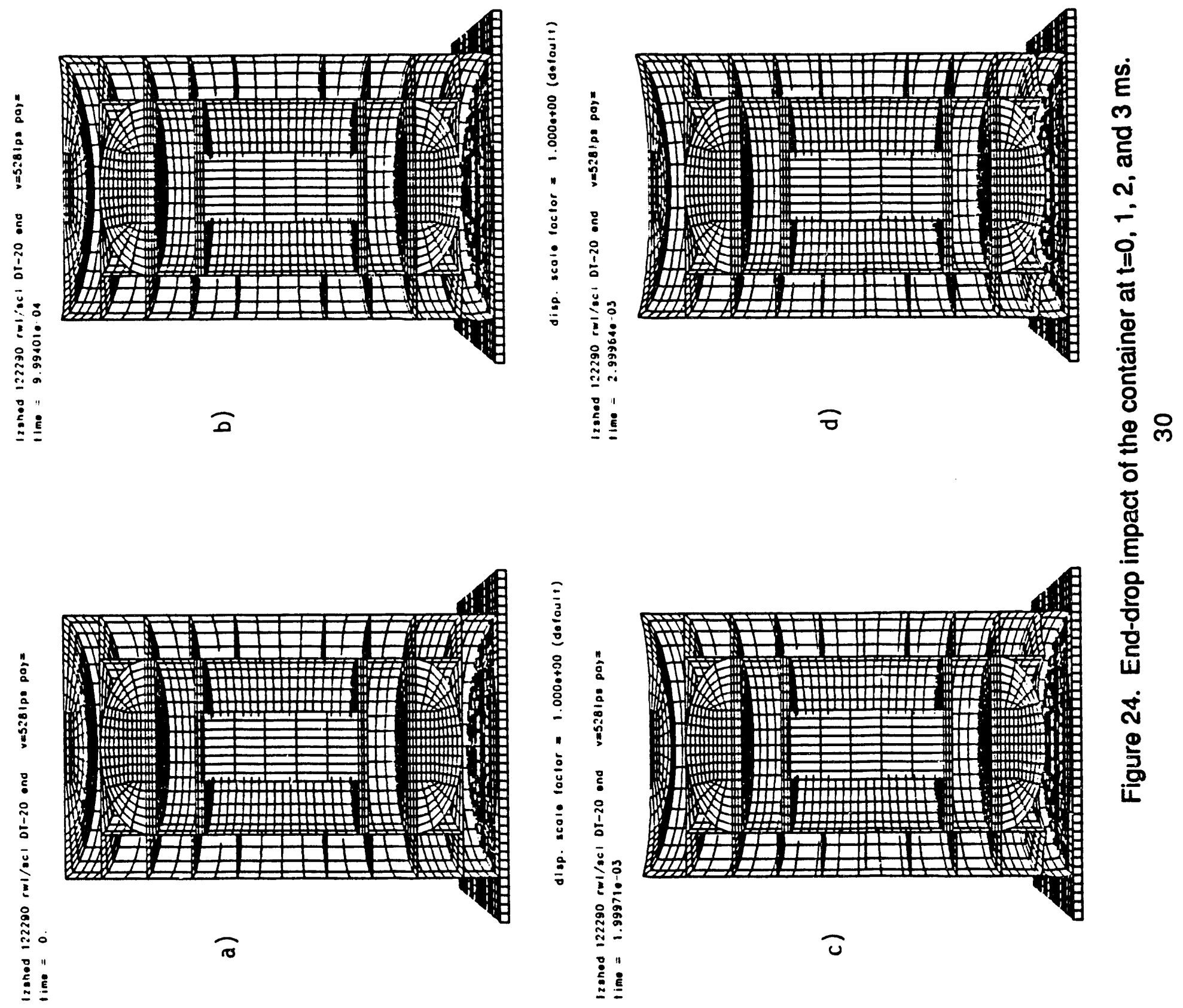

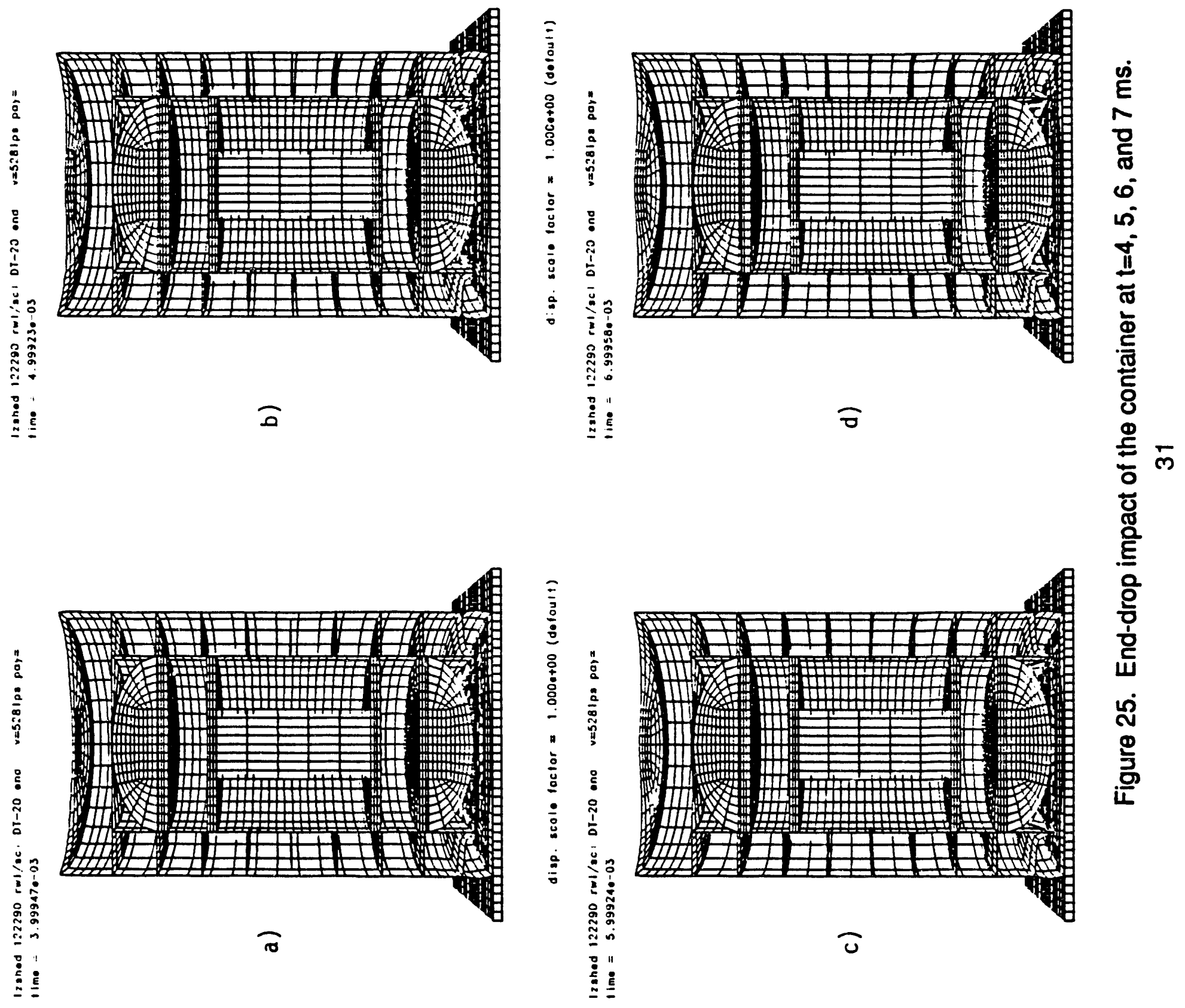

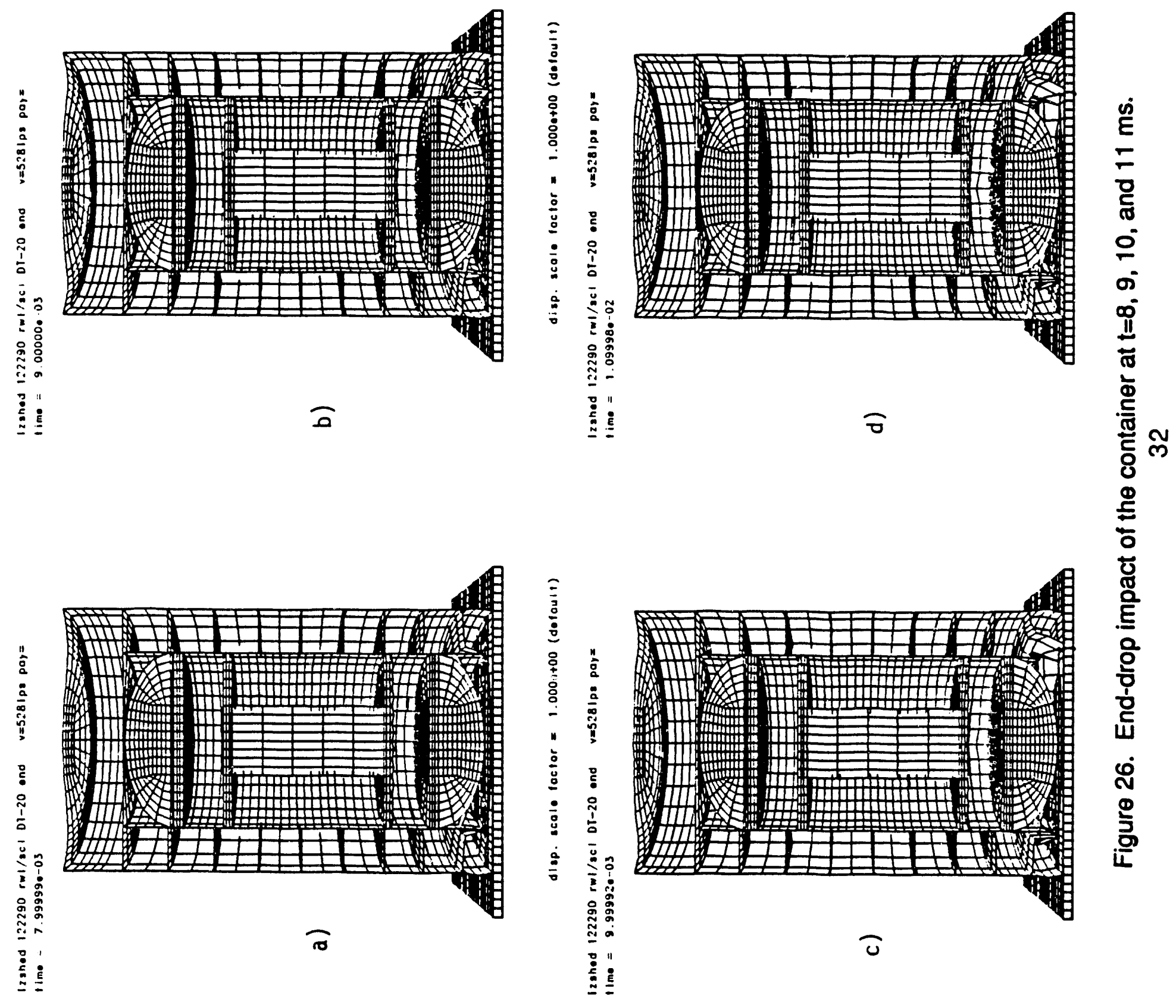


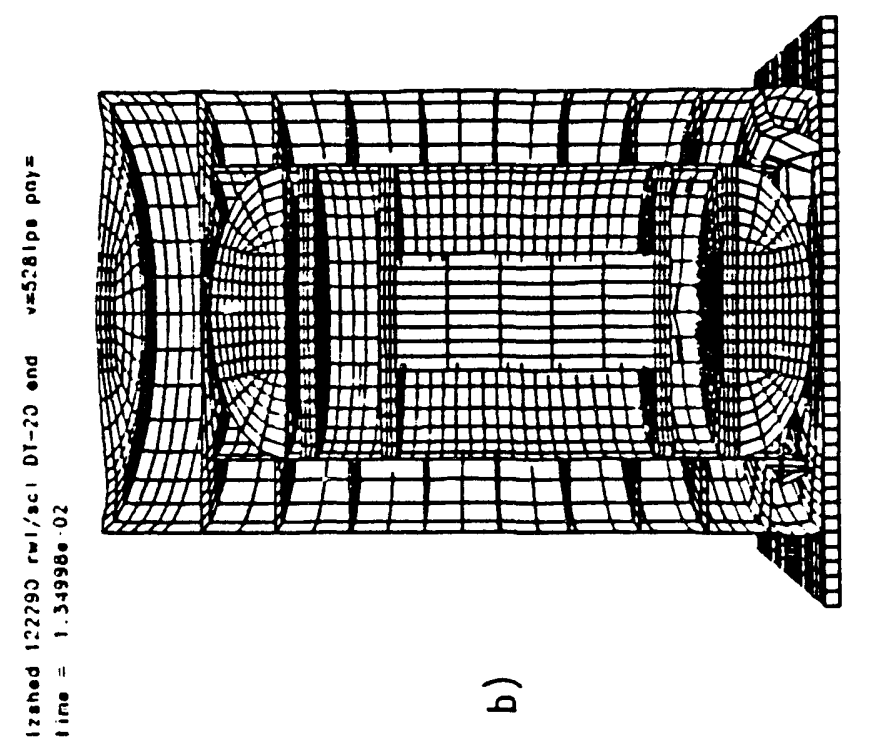

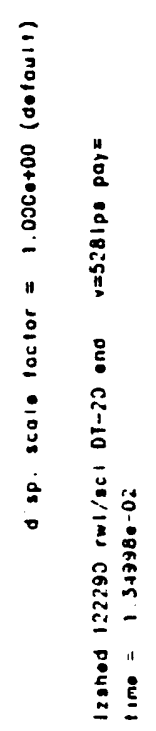

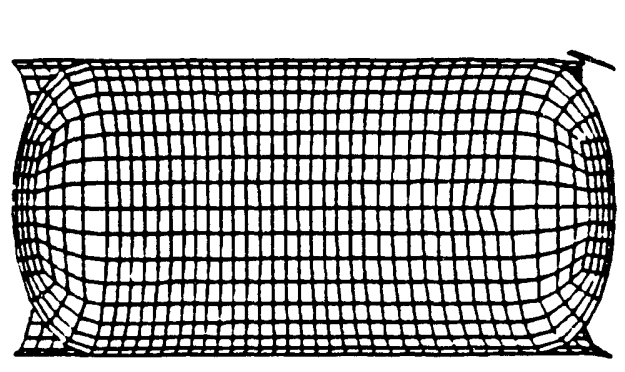

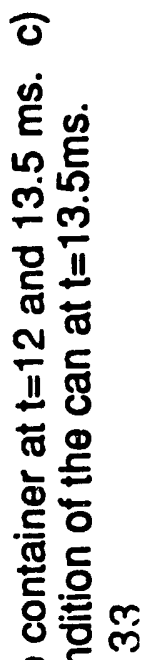

ㅇํㅇ

훙
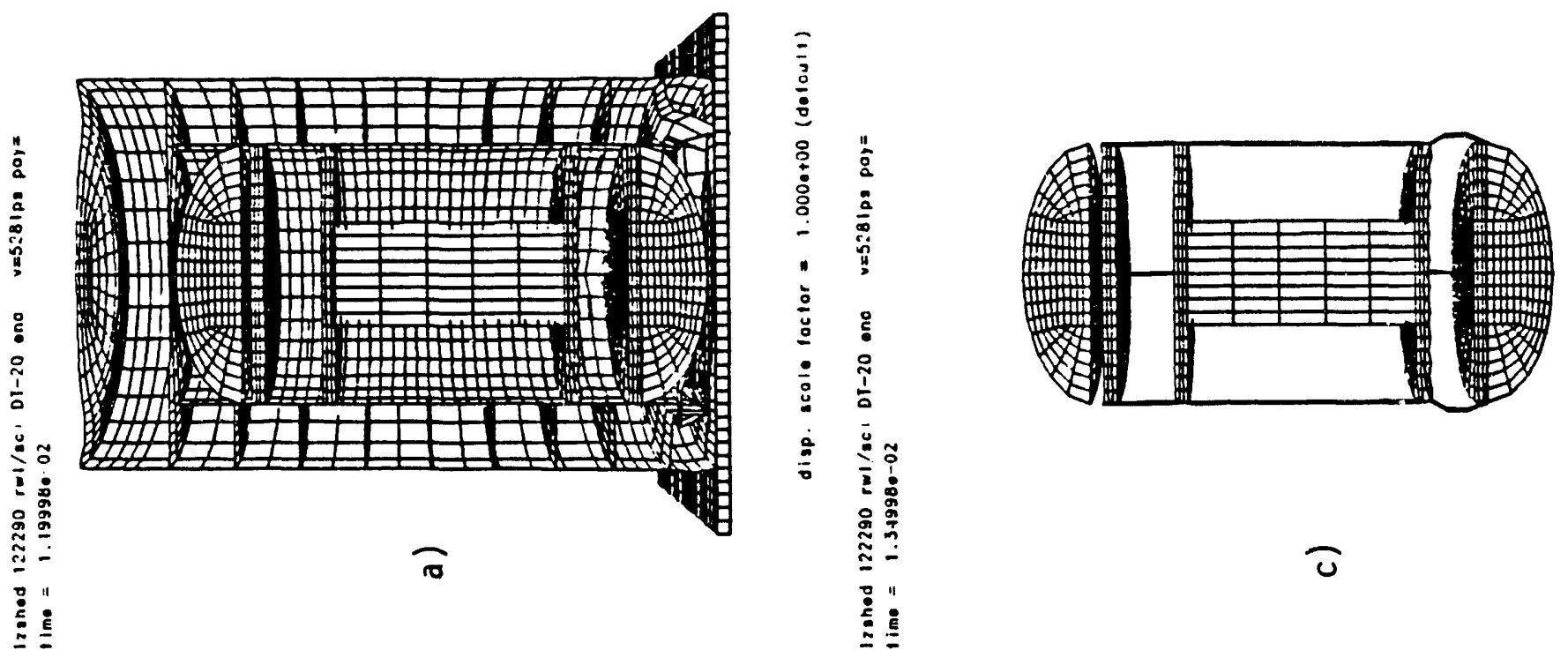

으롷

은 등

ํํㄹ 듕

岗里

ता

ลิ ธ

혼흉 

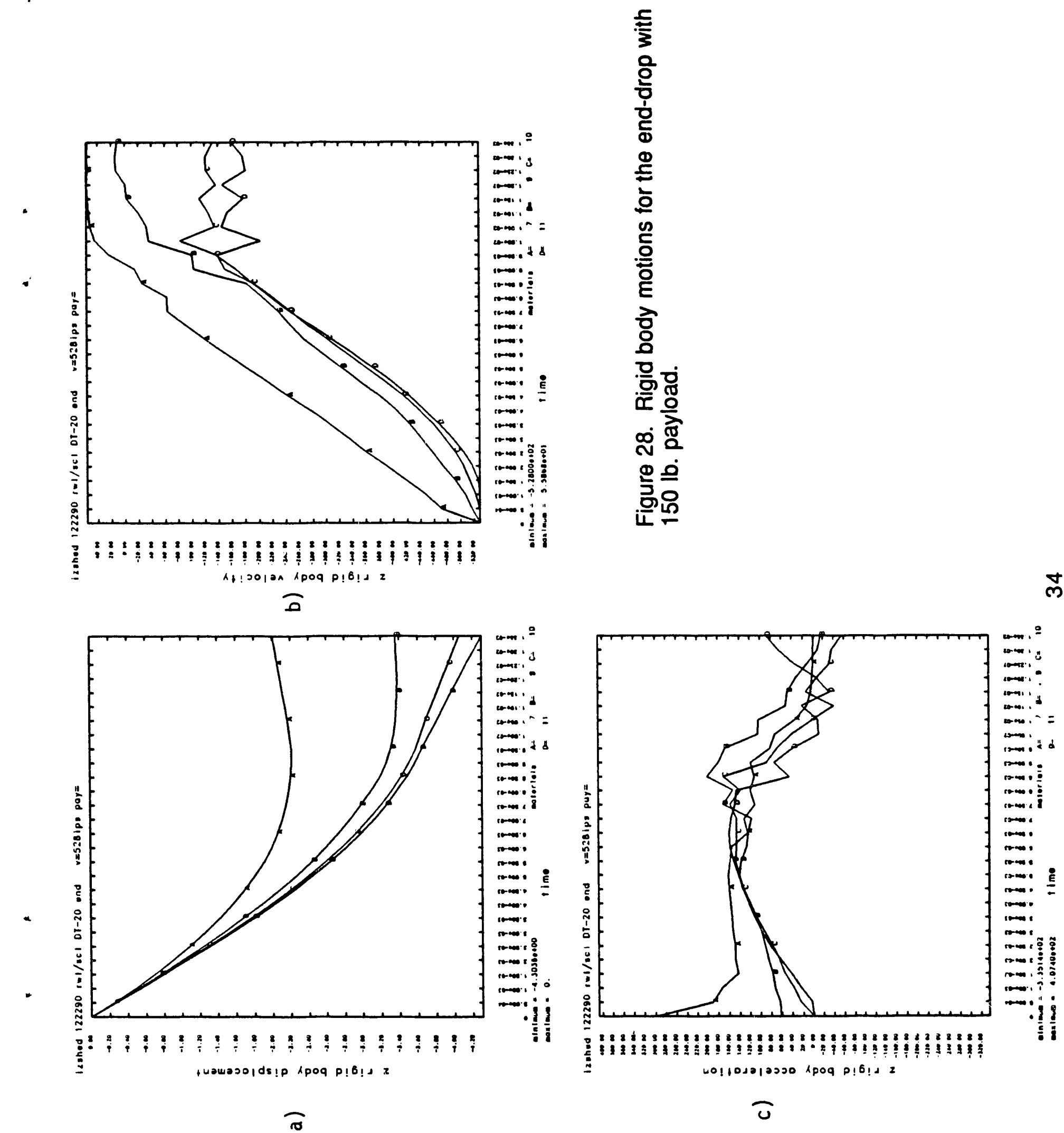

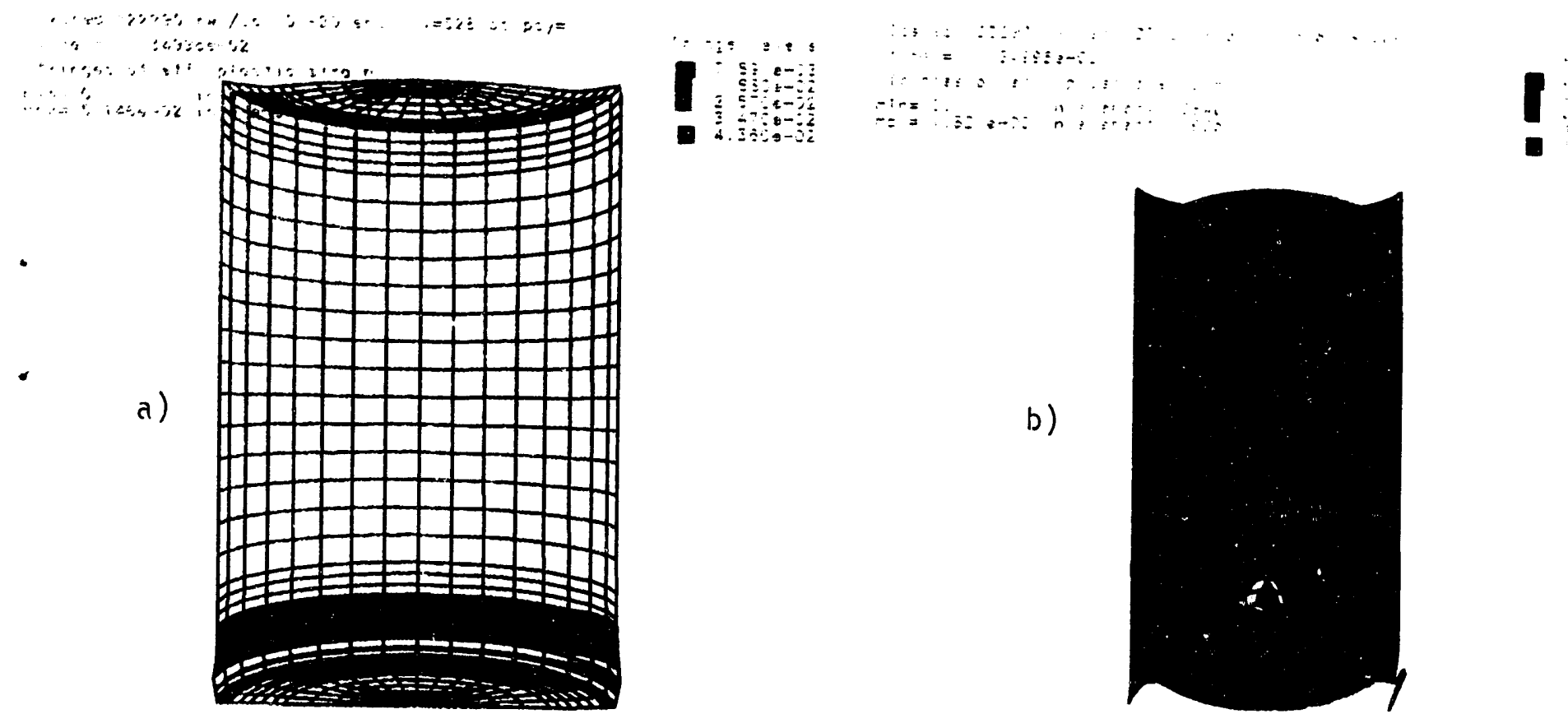

b)

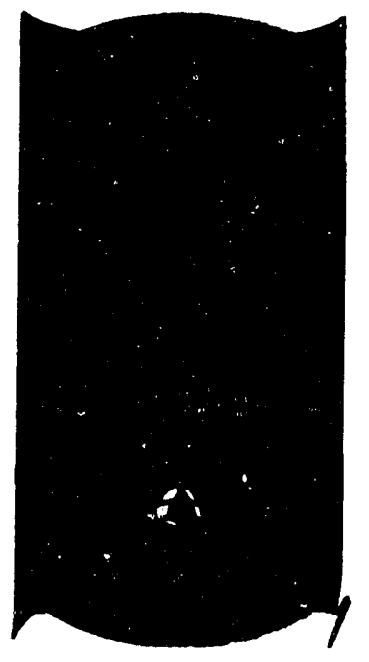

disp. scale foctor $=1.0000+00($ defoult $)$

i.rhed $1 \% 2901$, w1/sel $01-20$ und v-528ips poy $=$

tills $=1$, isg98e-02

fringe levels
$-1.0000-01$
$-3.0000-01$
$-2.000 e-01$
$-1.0000-01$
$-1.3320-15$

izshed 122290 /w1/sel DT 20 and

v"rip. pust

iningos of of plastic strain

mill...9.6/te of in vlement 139

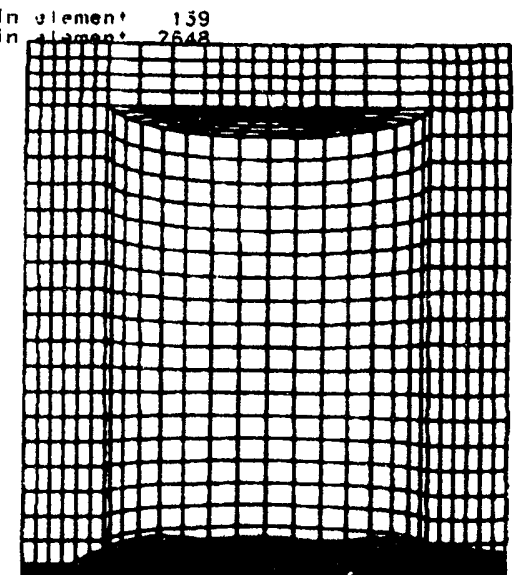

lime $=1.34998 \mathrm{e}-02$

fringes of $2-s t r a i n$

min $=-2.95: 0-02$ in lamen 3953
ma: $=-5.5640-04$ in lement 4366

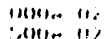

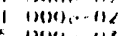

ma: $=-5.564 c-04$ in lement 4.366

i)

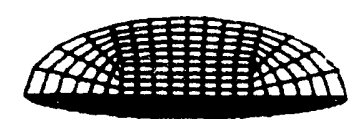

d)

c)
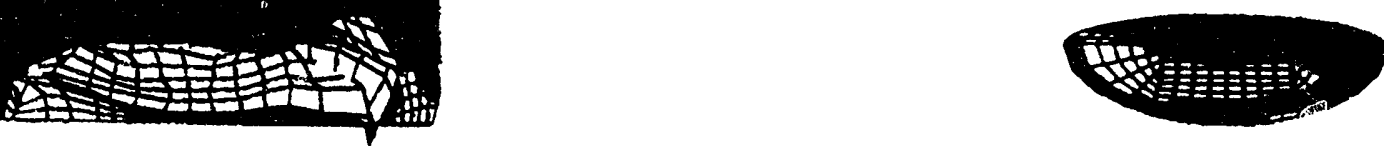

Figure 29. a) Plastic strain in the drum. b) Plastic strain in the can. Very high maxima are in the tangled mesh area. c) Volumetric strain in the Celotex. d) $Z$-strain (axial direction) in the honeycomb. 

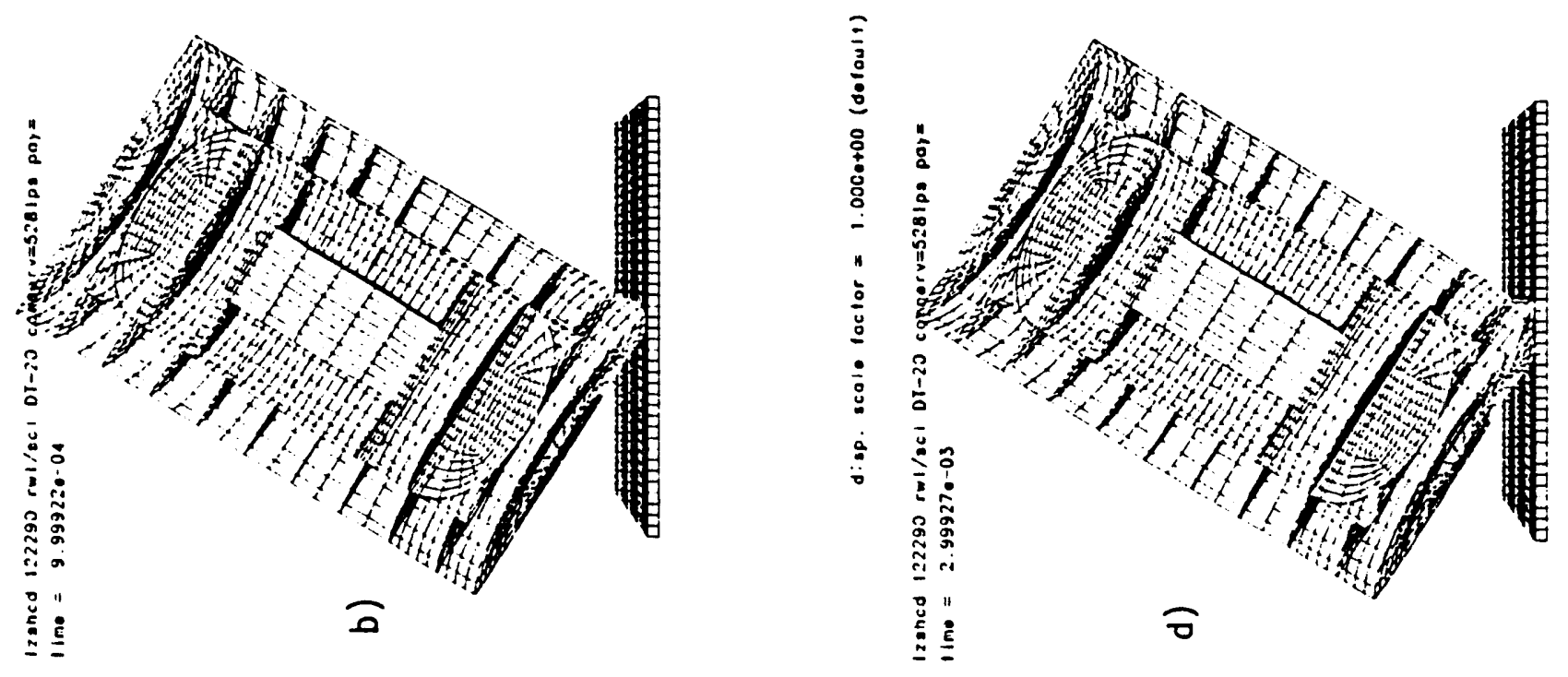

Eี

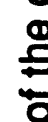
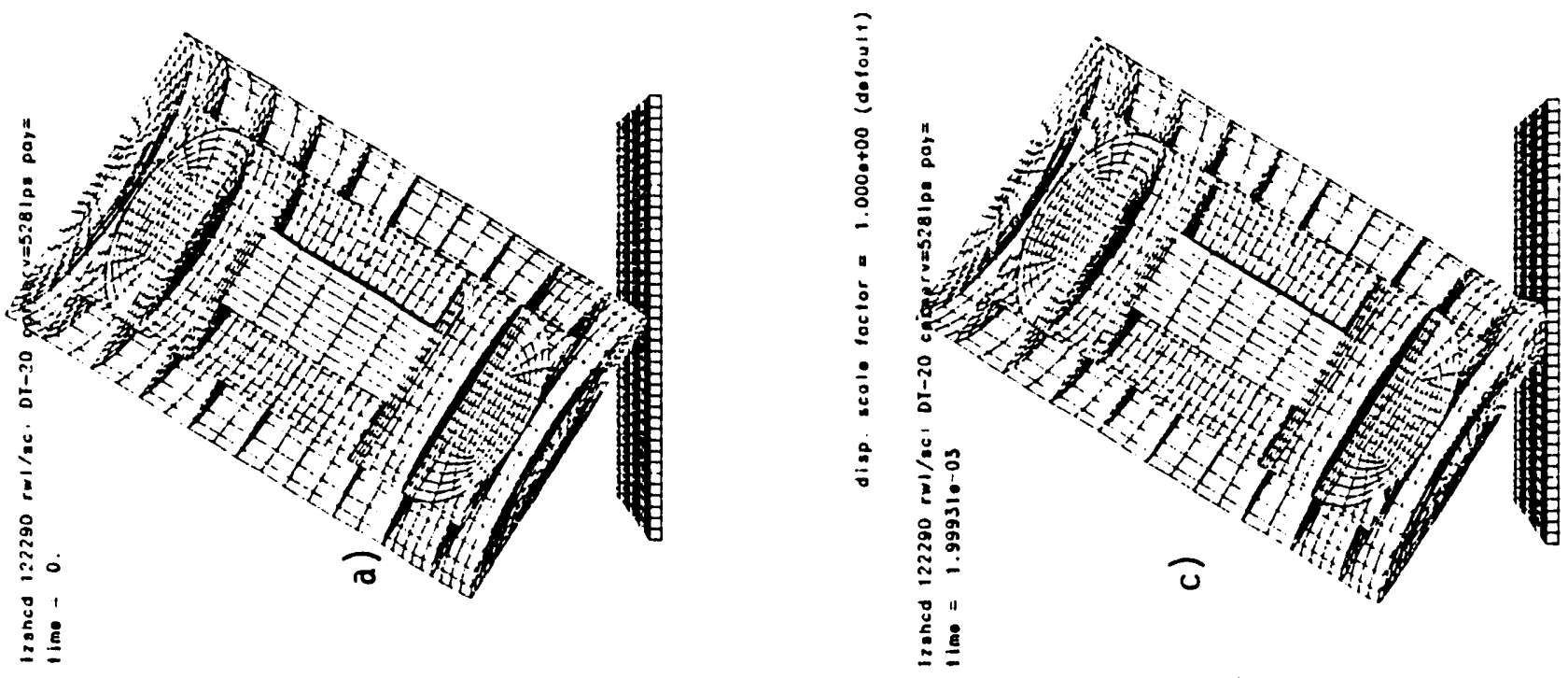

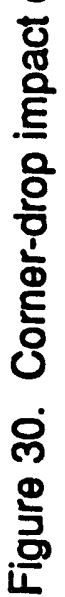



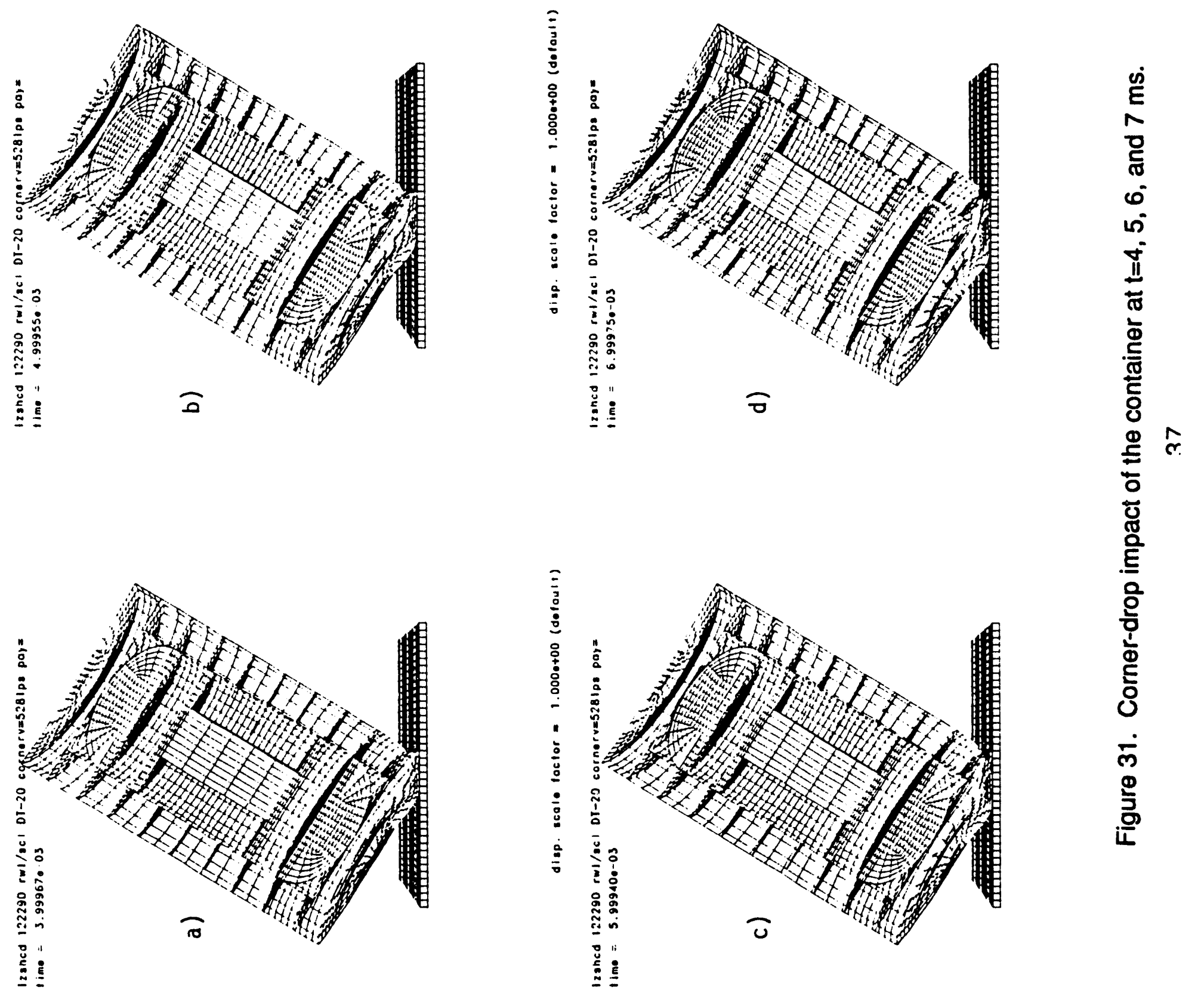

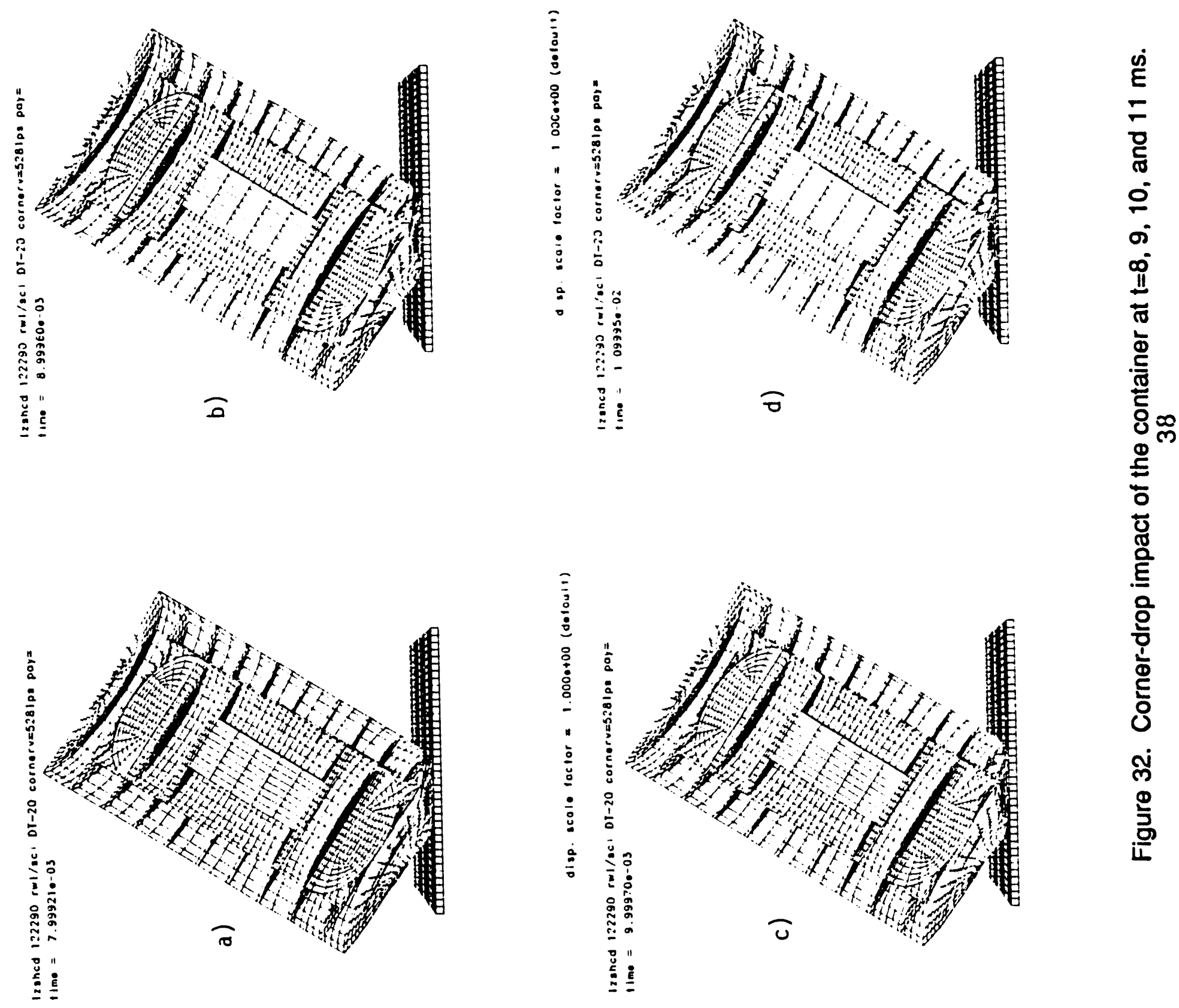

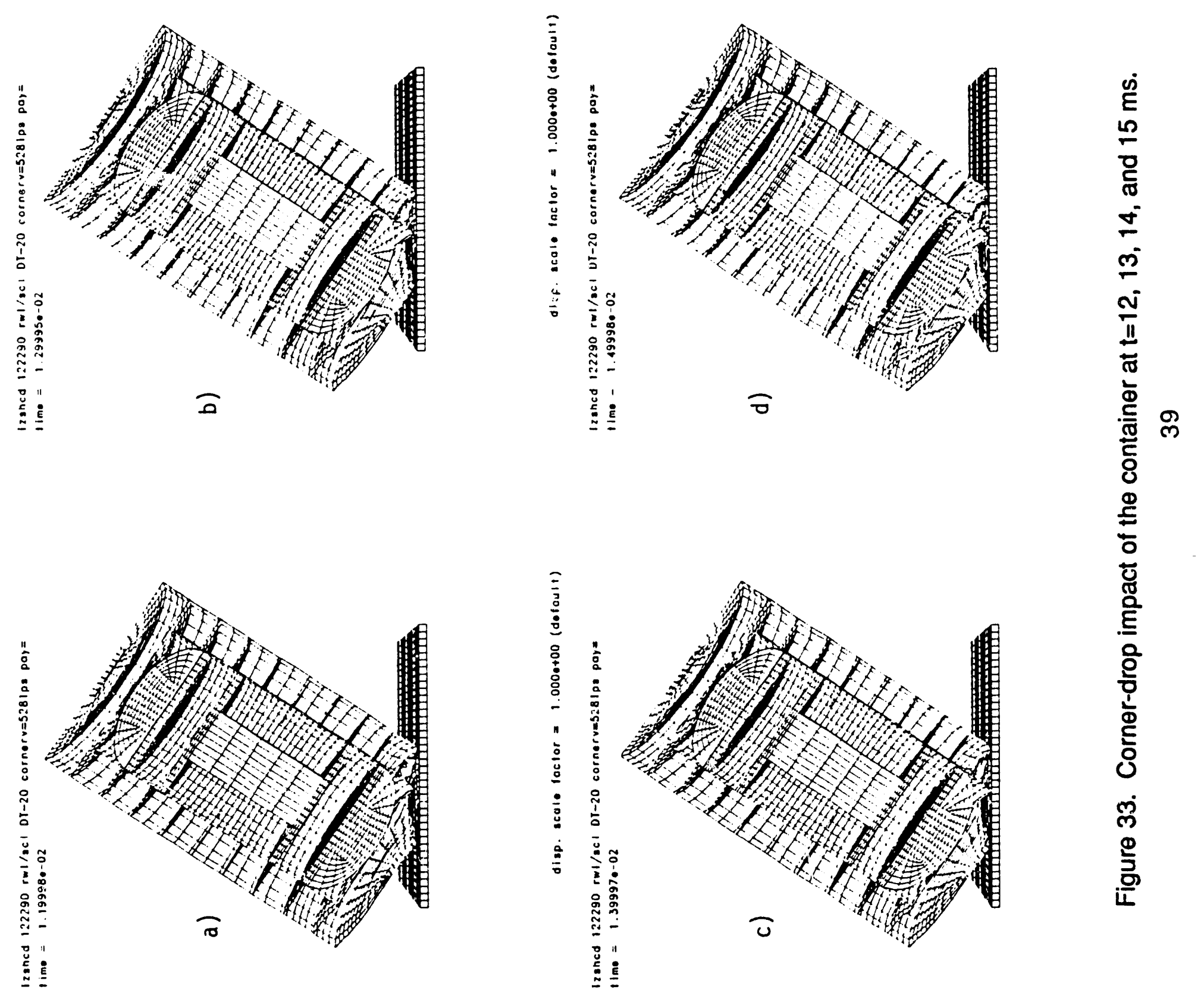

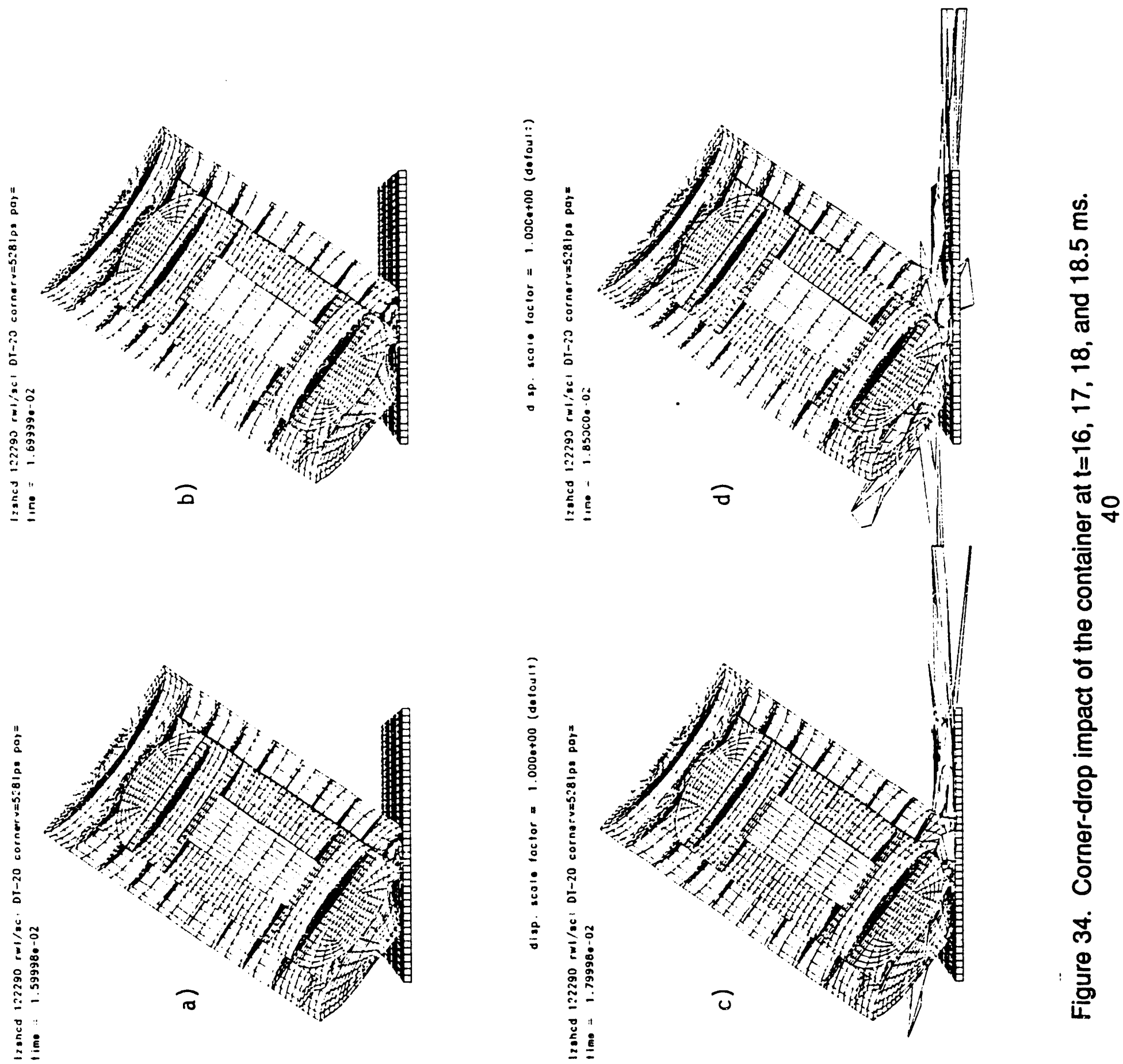


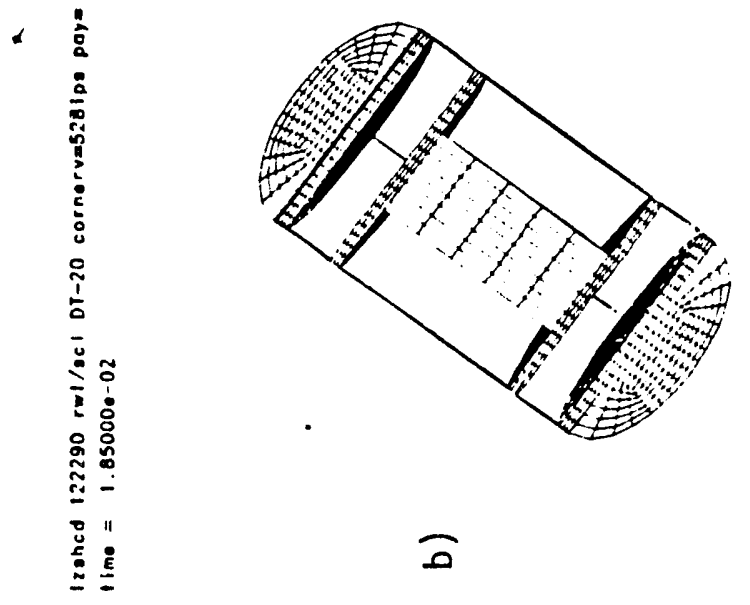

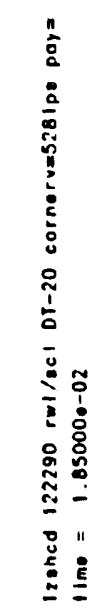
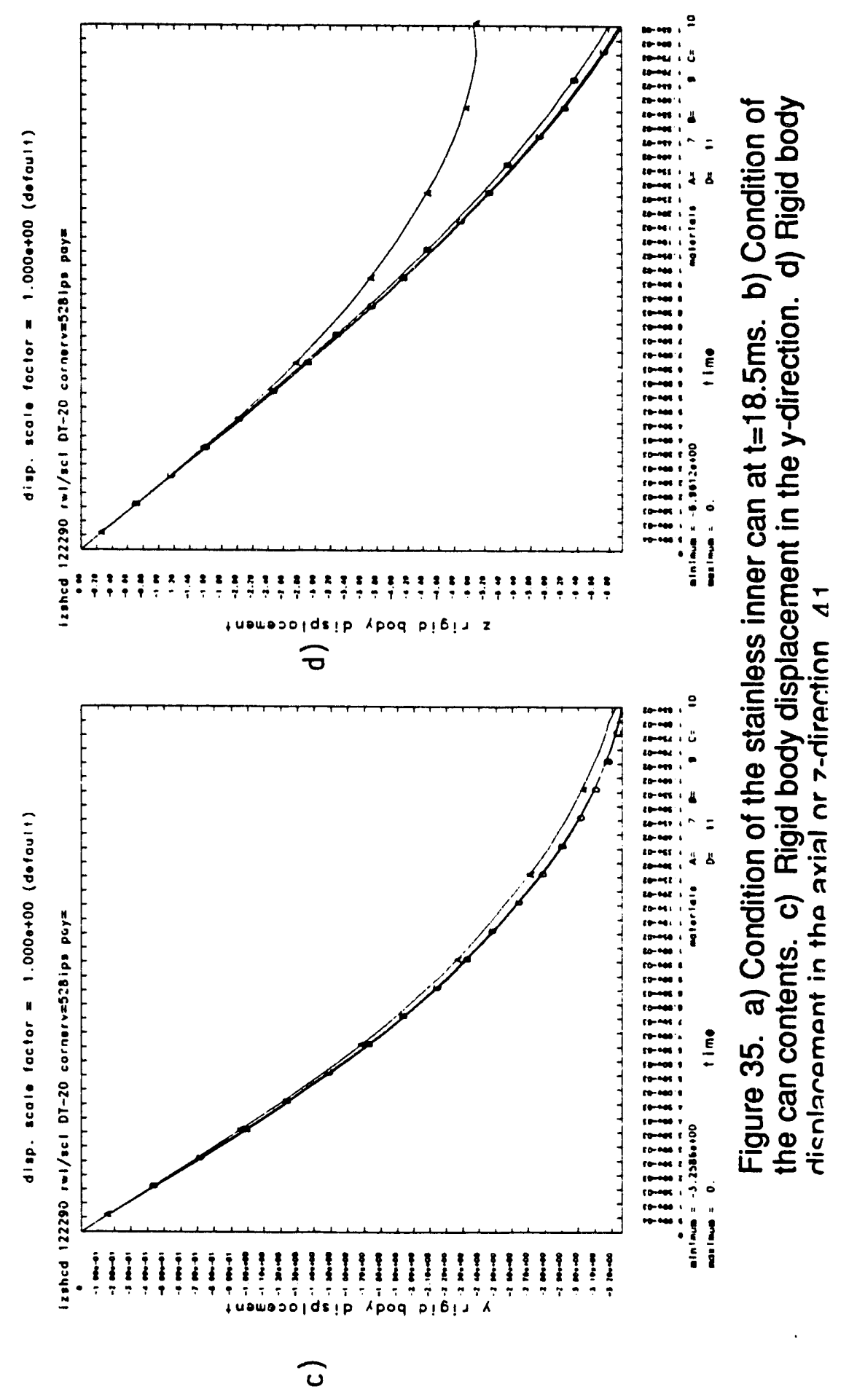


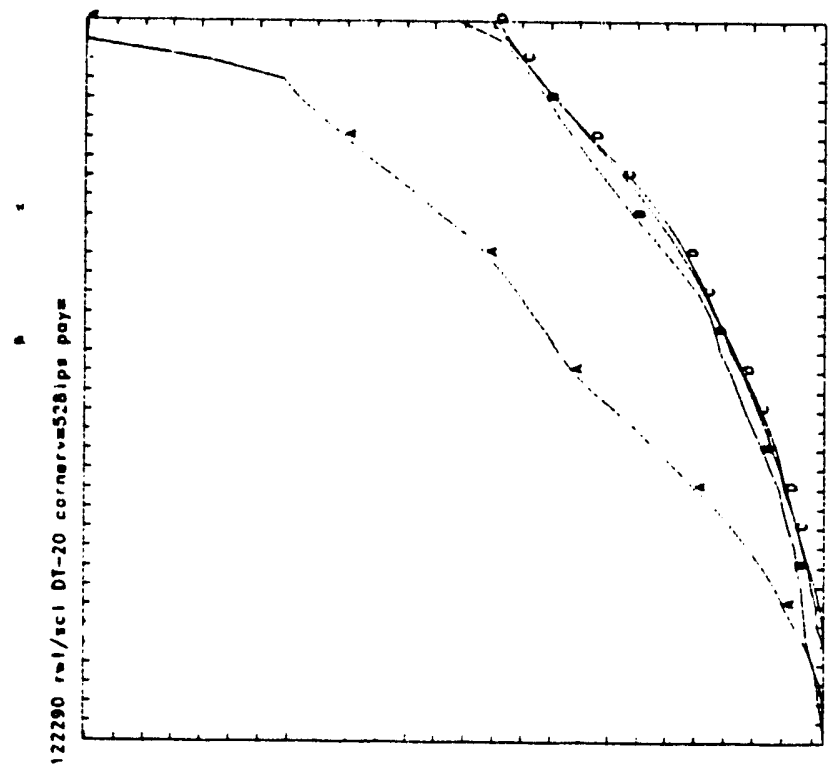

军: A\} solon lpoq p!b!J z

o

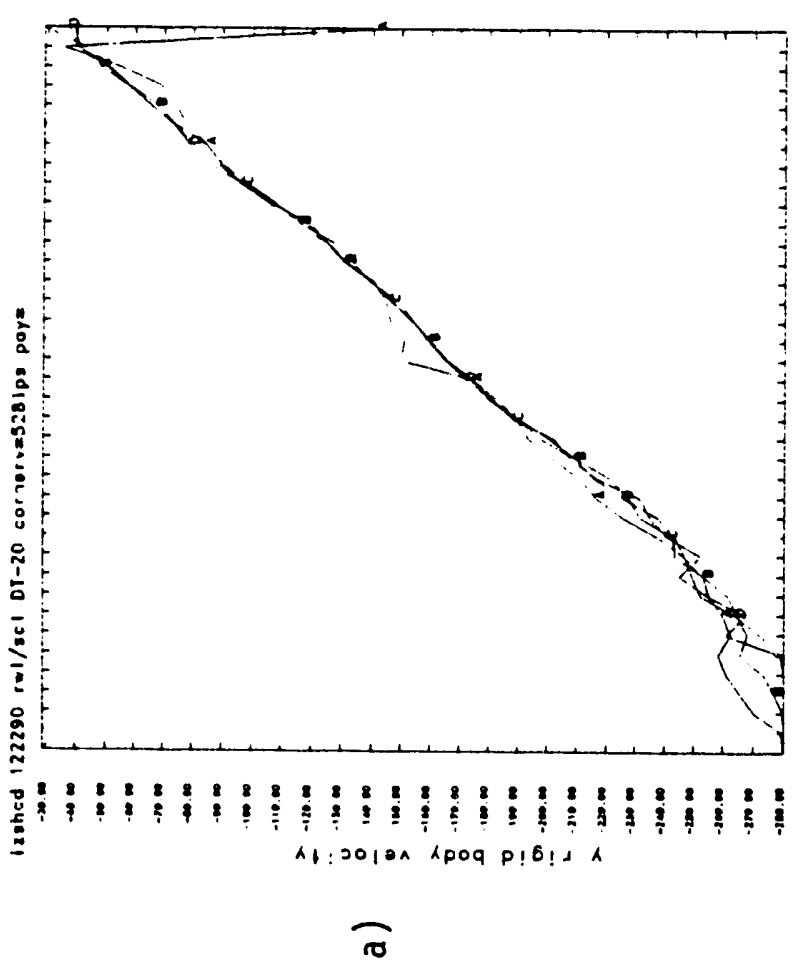

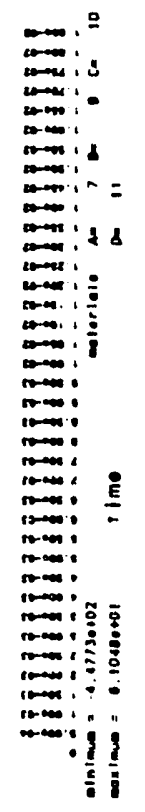

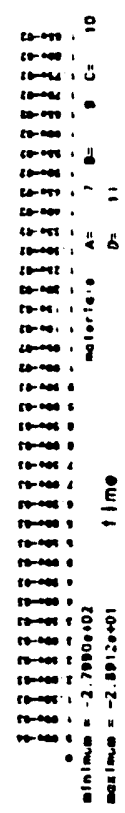

$\frac{1}{1}$

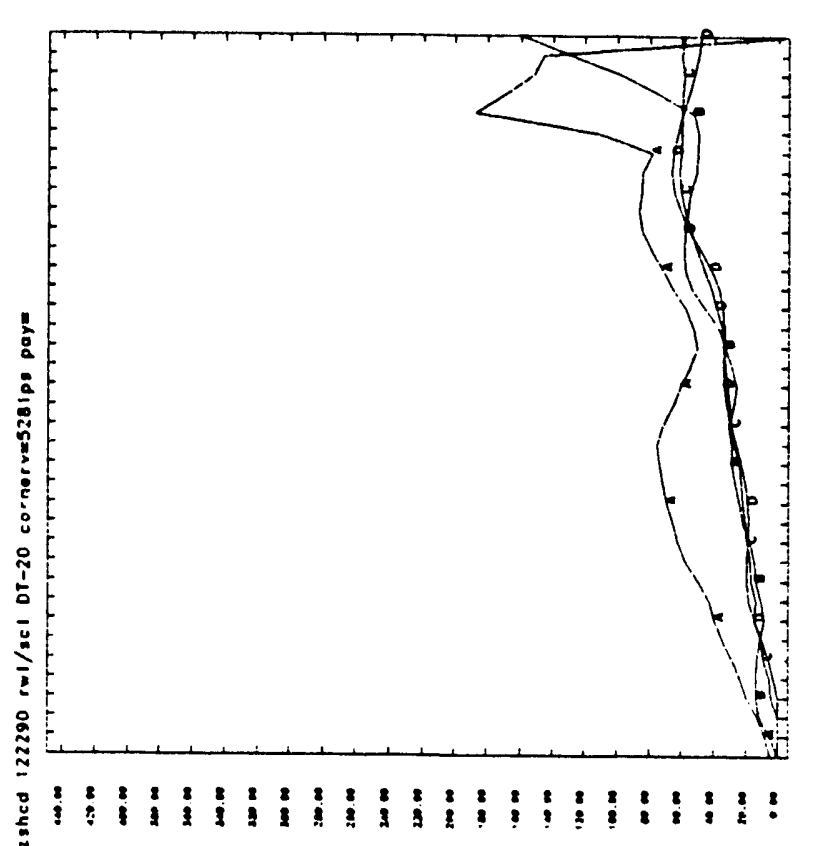

U०!101010000 ApOQ p!6!1 Z
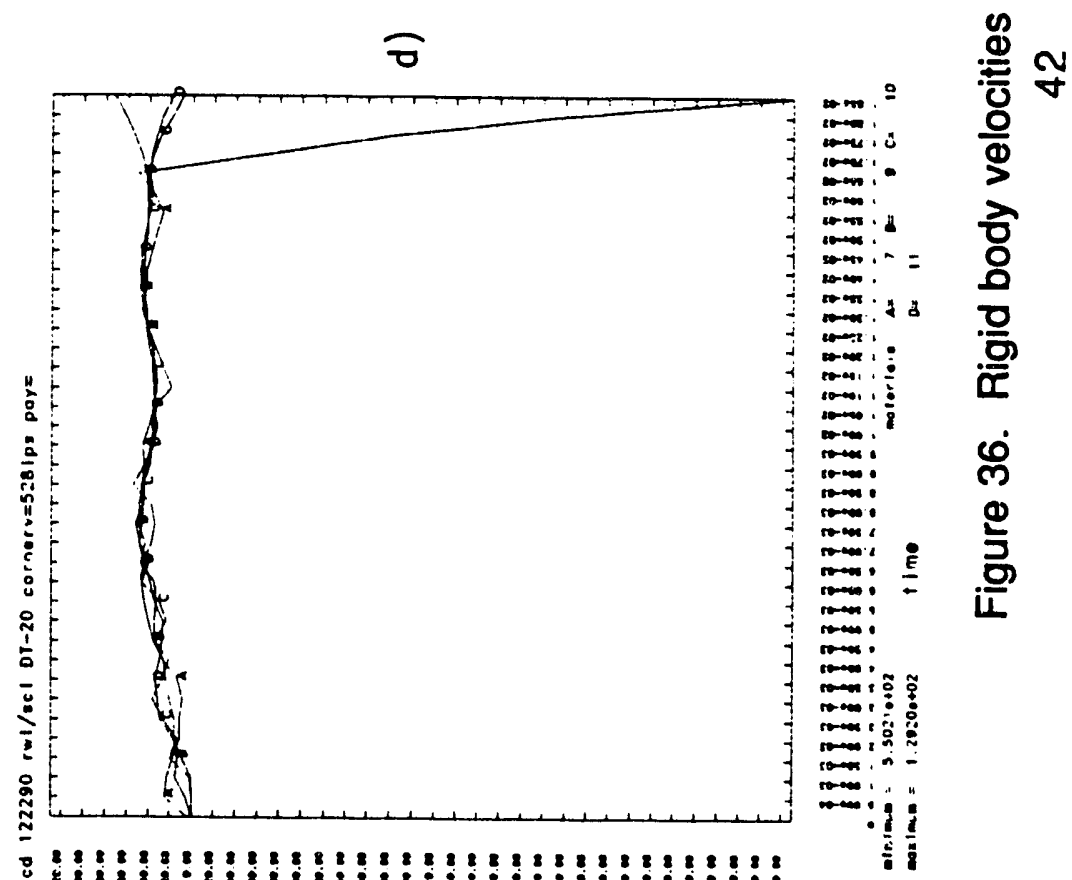

은 ๘
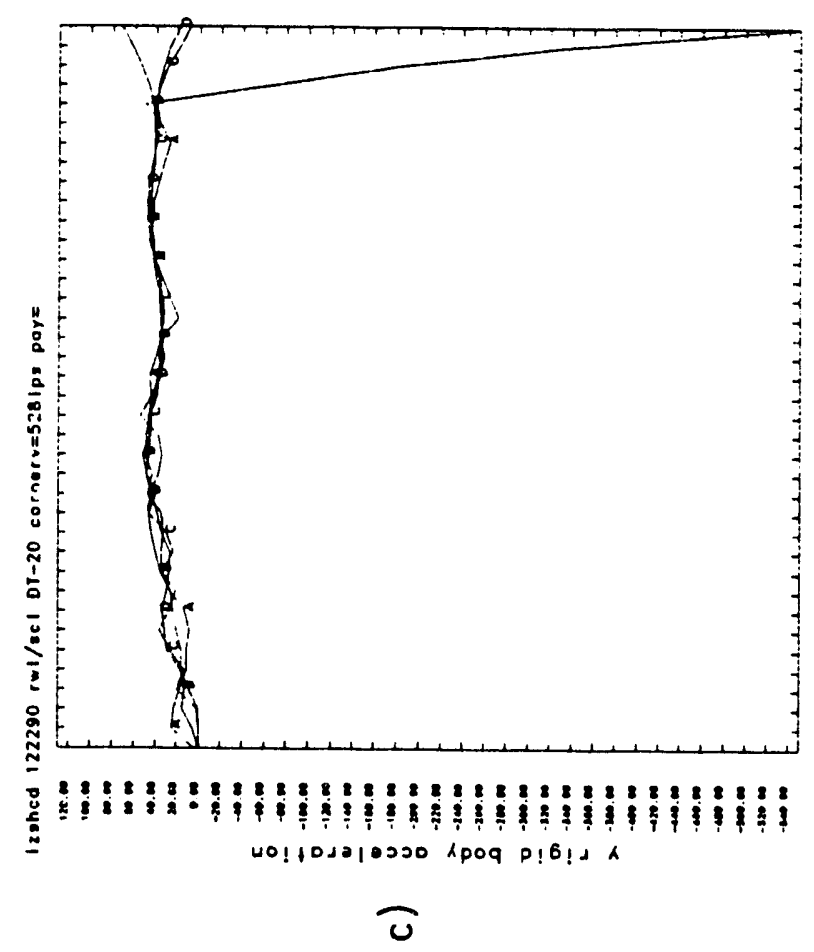

58 


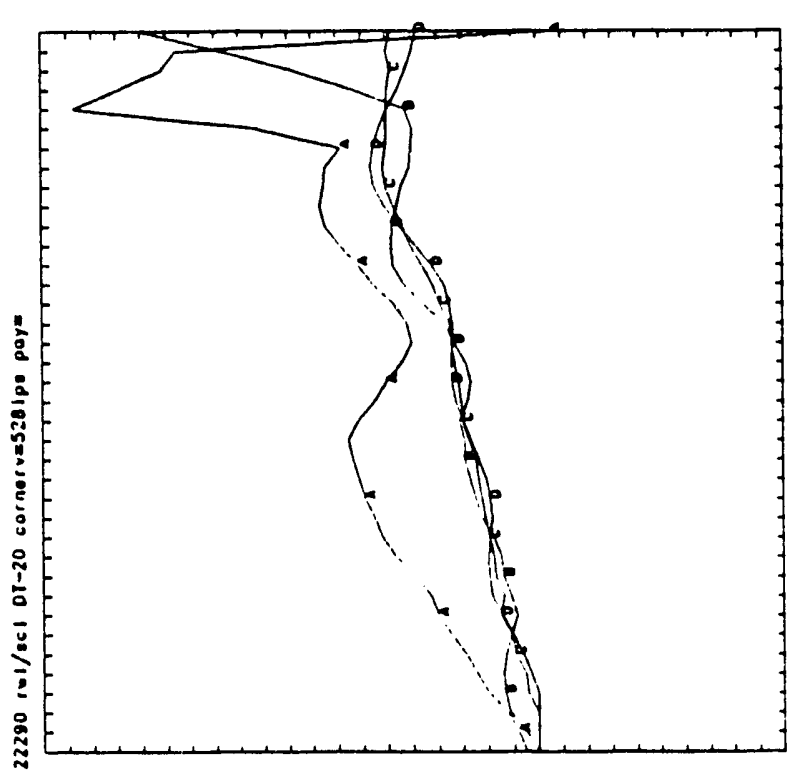

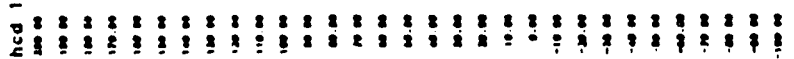

LO!101010000 ApOQ p!B!1 z

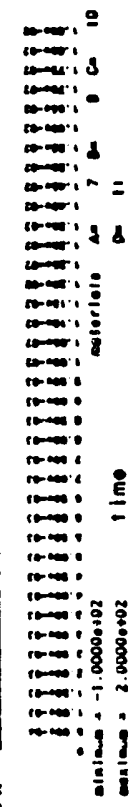

20

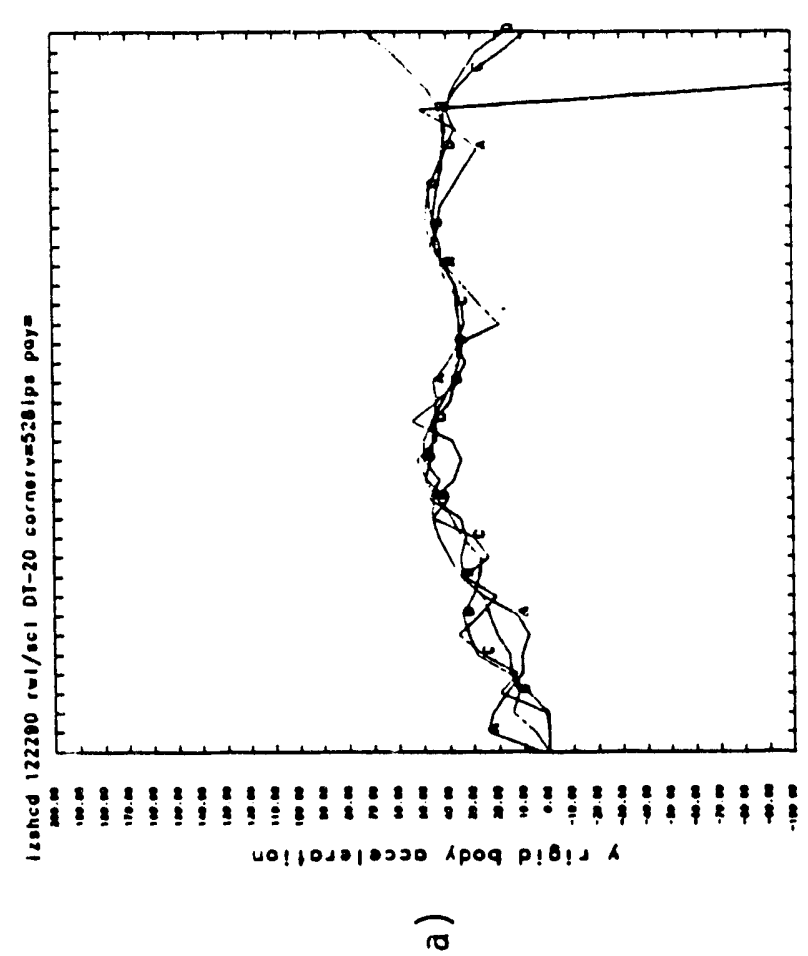

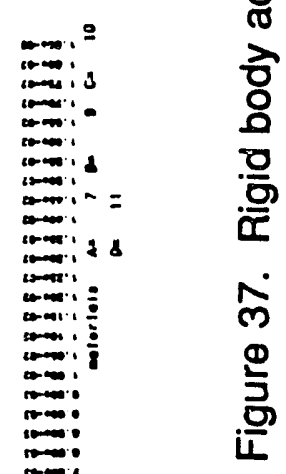


ieshed $122 \% 90 \mathrm{rwl} / \mathrm{sel}$ DT-20 cornerva528 ips poy=

line $=1.43993002$

iringas of aff. plastic strain

$\min =0$

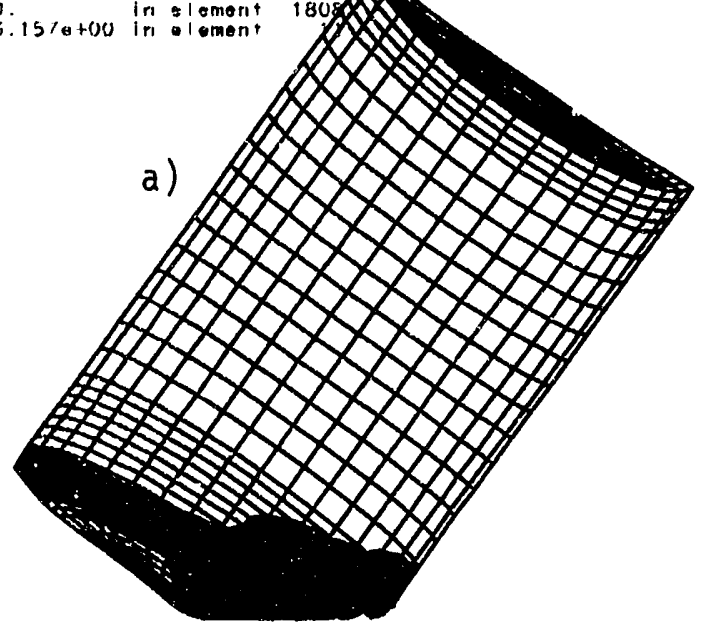

disp scisle factor $=1.000$ e +00 (default)

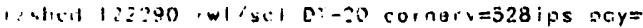

1 ine z. Tyugse-0z

Hirges at of plestic stia'r

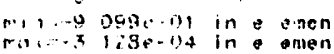

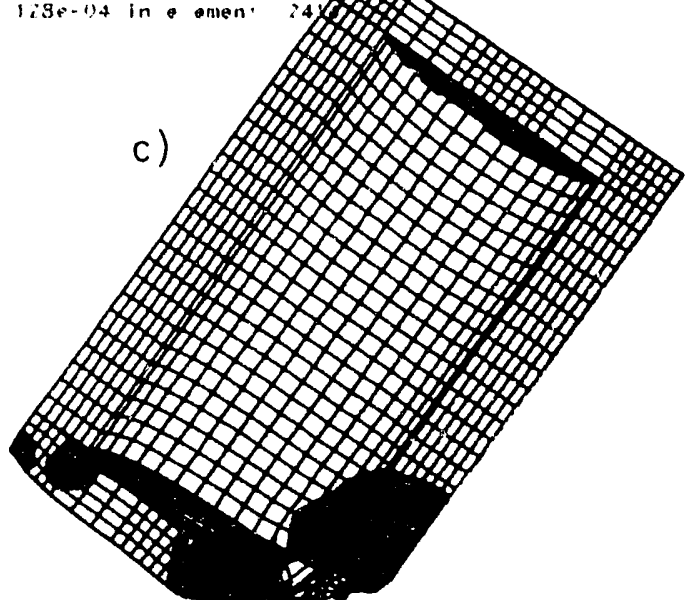

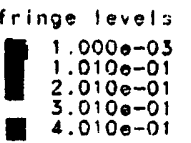

izsted $122290 \mathrm{rwl} / \mathrm{s}=1$ DT-?0 cernetl=5?

ting $=1.599980-02$

fringes of eff. plostiz stion

$\min =0$.

n slement 2040

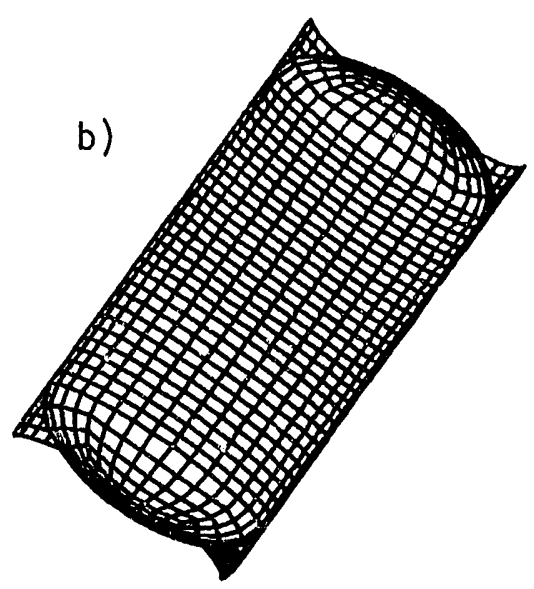

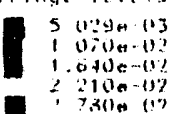




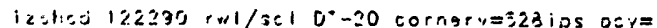

1 ine $=3.999670-03$

fririggs of 2 stross

mi $=-1.3 E 70+0$, in $a$ emen
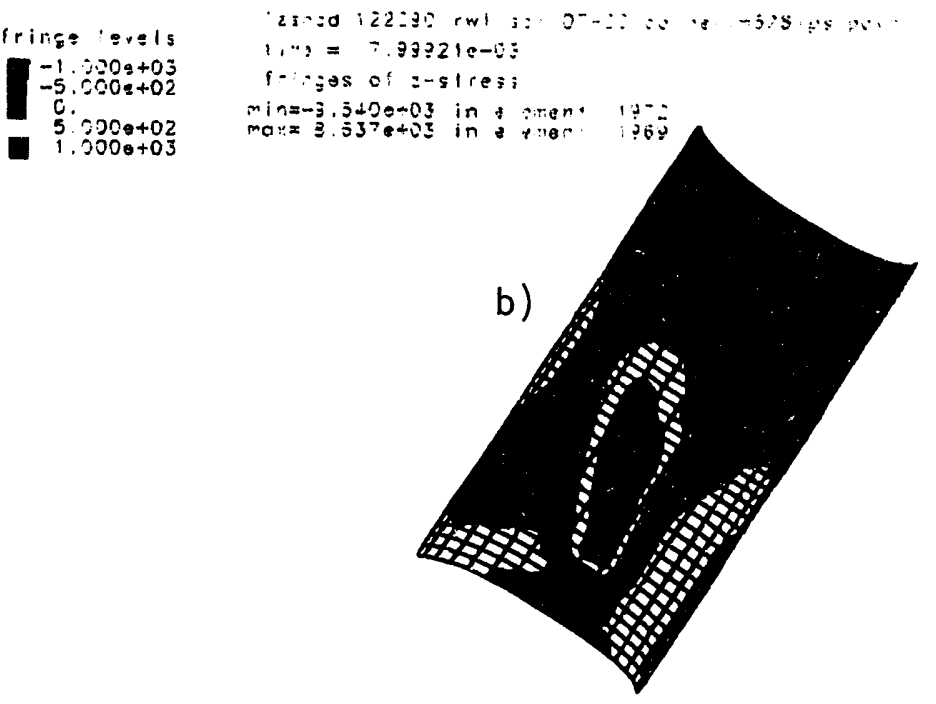

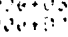

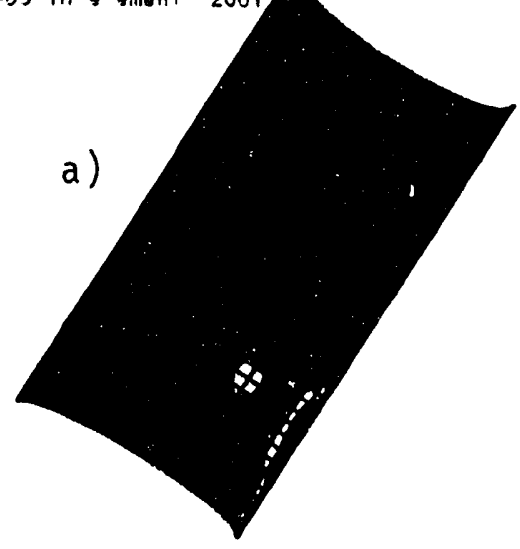

$2 x+2$

disp. scale factor $=1.0000+00($ defoult $)$

i inhed 122"90 rwl/scl or-20 cornerva528ips poy=

i ime $=1.199980-02$

fringe level:

$-1.000 \bullet+03$
$-5.0000+02$

$0.0000+02$
$5.000 e+03$

min=-1.7000+03 in element 1969

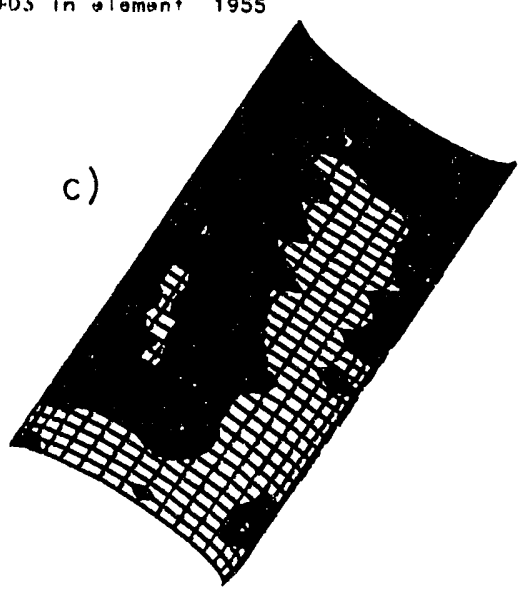

izshed $122290 \mathrm{rwl} / \mathrm{sel}$ OT -20 cornerva528ips poy:

time $=1.59998 \mathrm{e}-02$

fringes of z-stross

min=-1.692c+04 in clement 1969
mans=1.2610+04 in element 1971

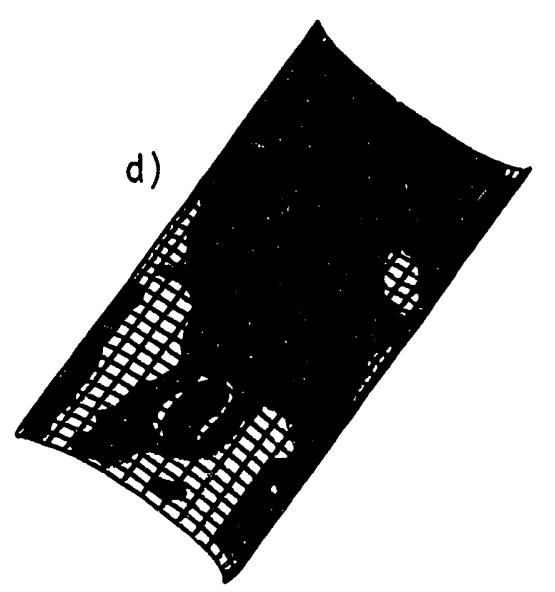

Prinue level:

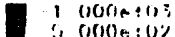

a.

is $1,000+1,102$

Figure 39. Axial stresses in the can at $t=4,8,12$, and $16 \mathrm{~ms}$. 


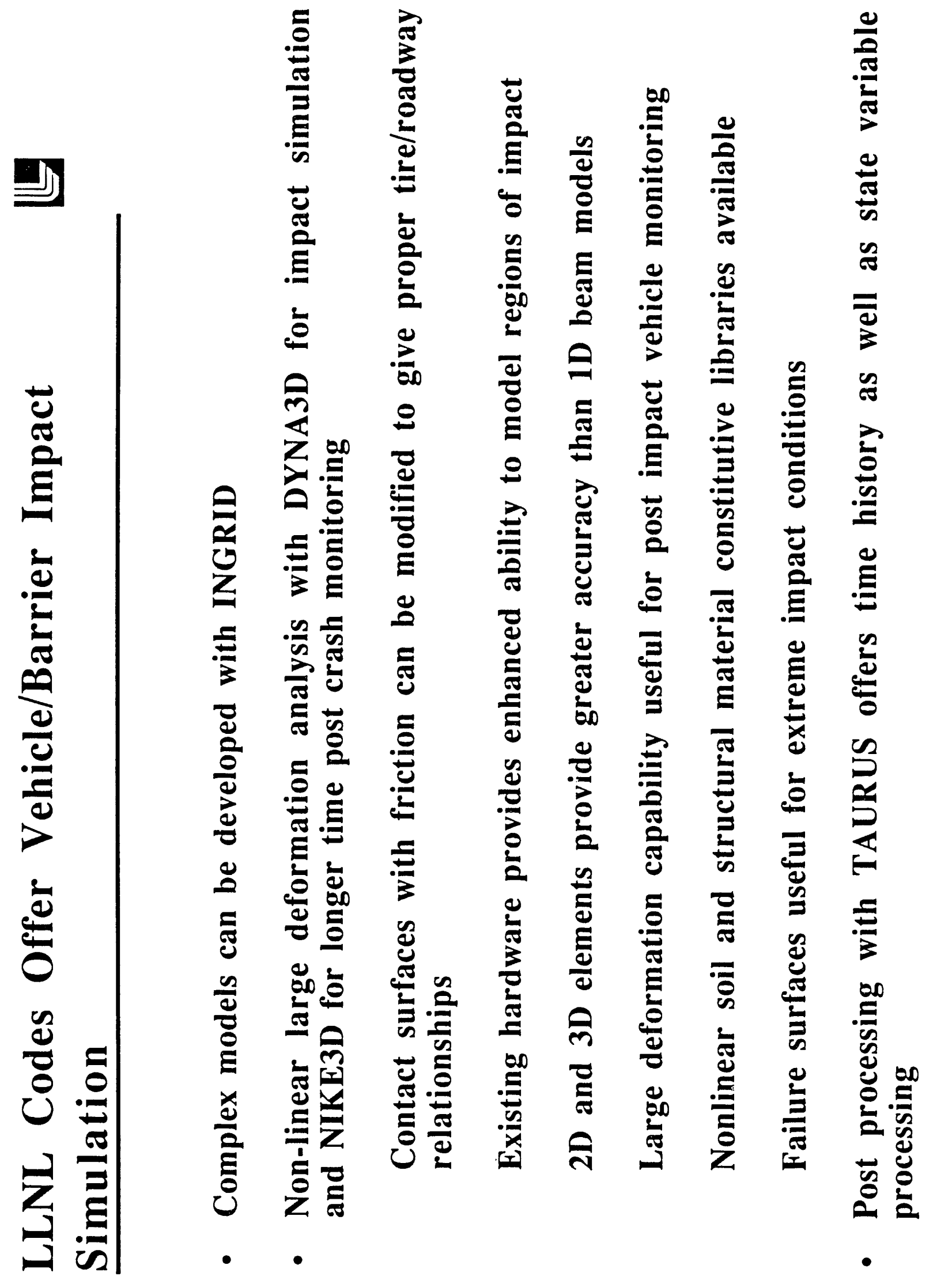


CURRENT

CODES
TIRE

MODEL
UCD

INPUTS
DYNA/NIKE

ANALYSIS DEVELOPMENT

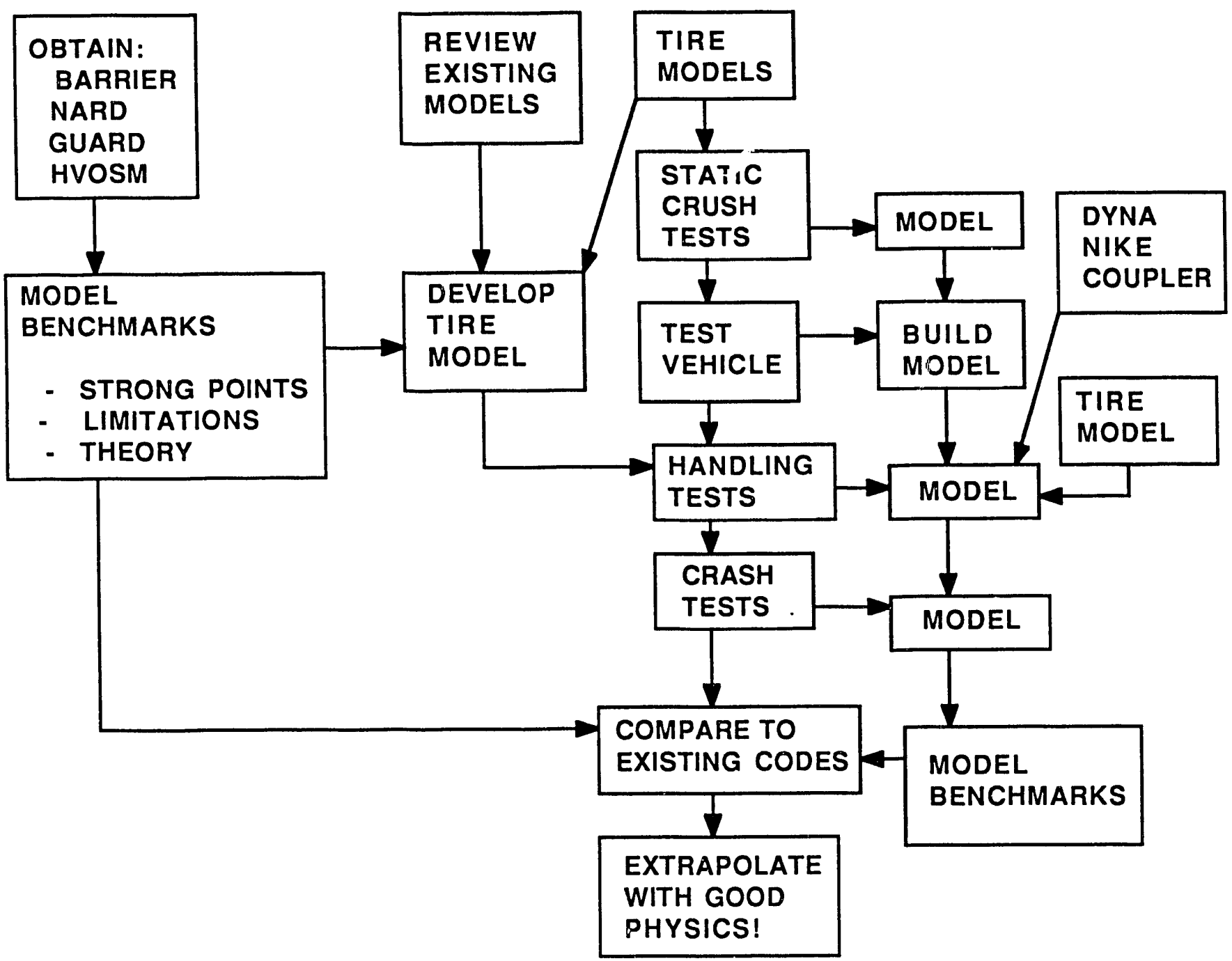


